\title{
The price of innovation: new estimates of drug development costs
}

\author{
Joseph A. DiMasi ${ }^{\text {a,*, Ronald W. Hansen }}{ }^{\mathrm{b}}$, Henry G. Grabowski ${ }^{\mathrm{c}}$ \\ a Tufts Center for the Study of Drug Development, Tufts University, 192 South Street, \\ Suite 550, Boston, MA 02111, USA \\ ${ }^{\mathrm{b}}$ William E. Simon Graduate School of Business Administration, University of Rochester, Rochester, NY, USA \\ c Department of Economics, Duke University, Durham, NC, USA
}

Received 17 January 2002; received in revised form 24 May 2002; accepted 28 October 2002

\begin{abstract}
The research and development costs of 68 randomly selected new drugs were obtained from a survey of 10 pharmaceutical firms. These data were used to estimate the average pre-tax cost of new drug development. The costs of compounds abandoned during testing were linked to the costs of compounds that obtained marketing approval. The estimated average out-of-pocket cost per new drug is US $\$ 403$ million (2000 dollars). Capitalizing out-of-pocket costs to the point of marketing approval at a real discount rate of $11 \%$ yields a total pre-approval cost estimate of US\$ 802 million (2000 dollars). When compared to the results of an earlier study with a similar methodology, total capitalized costs were shown to have increased at an annual rate of $7.4 \%$ above general price inflation. (C) 2003 Elsevier Science B.V. All rights reserved.
\end{abstract}

JEL classification: L65; O31

Keywords: Innovation; R\&D cost; Pharmaceutical industry; Discount rate; Technical success rates

\section{Introduction}

Innovations in the health sciences have resulted in dramatic changes in the ability to treat disease and improve the quality of life. Expenditures on pharmaceuticals have grown faster than other major components of the health care system since the late 1990s. Consequently, the debates on rising health care costs and the development of new medical technologies have focused increasingly on the pharmaceutical industry, which is both a major participant in the health care industry and a major source of advances in health care technologies.

\footnotetext{
* Corresponding author. Tel.: +1-617-636-2116.

E-mail address: joseph.dimasi@tufts.edu (J.A. DiMasi).
} 
One of the key components of the discussion is the role of private sector pharmaceutical industry investments in R\&D and an understanding of the factors that affect this process. Although the industry engages in many forms of innovation, in general the most significant is the discovery and development of new chemical and biopharmaceutical entities that become new therapies. Our prior research (DiMasi et al., 1991) found that the discovery and development of new drugs is a very lengthy and costly process. In the research-based drug industry, R\&D decisions have very long-term ramifications, and the impact of market or public policy changes may not be fully realized for many years. From both a policy perspective, as well as an industrial perspective, it is therefore important to continue to analyze the components of and trends in the costs of pharmaceutical innovation.

In this paper we will build on research conducted by the current authors (DiMasi et al., 1991) and others on the economics of pharmaceutical R\&D. As we described in our prior study, "Empirical analyses of the cost to discover and develop NCEs are interesting on several counts. First, knowledge of $R \& D$ costs is important for analyzing issues such as the returns on $R \& D$ investment. Second, the cost of a new drug has direct bearing on the organizational structure of innovation in pharmaceuticals. In this regard, higher real $\mathrm{R} \& \mathrm{D}$ costs have been cited as one of the main factors underlying the recent trend toward more mergers and industry consolidation. Third, R\&D costs also influence the pattern of international resource allocation. Finally, the cost of R\&D has become an important issue in its own right in the recent policy deliberations involving regulatory requirements and the economic performance of the pharmaceutical industry". In the decade that has followed the publication of our earlier study, these issues remain paramount. In addition, the congressional debates on Medicare prescription drug coverage and various new state initiatives to fill gaps in coverage for the elderly and the uninsured have intensified the interest in the performance of the pharmaceutical industry.

In the current study we are not attempting to directly answer the policy debates mentioned above. Rather, our focus is on providing new estimates of economic parameters associated with the drug development process. In particular, we concentrate on estimates of the costs of pharmaceutical innovation. Our prior estimates have been used by the Office of Technology assessment (OTA), the Congressional Budget Office (CBO), and various researchers to analyze policy questions such as the effects on $R \& D$ activities of health care financing reform or changes in intellectual property legislation related to the pharmaceutical industry.

The approach used in this paper follows our previous study (DiMasi et al., 1991) and the earlier work by Hansen (1979). Given the similarity in methodologies, we are able to compare our results in the current study with the estimates in the earlier studies to illustrate trends in development costs. All three studies used micro-level data on the cost and timing of development obtained through confidential surveys of pharmaceutical firms for a random sample of new drugs first investigated in humans by these firms. In the current study, the new drugs were first tested in humans anywhere in the world between 1983 and 1994. The reported development costs ran through 2000.Ultimately, we are interested in the expected cost of development per approved new drug. The uncertainties in the research and development process result in expenditures on many development projects that are not successful in producing a marketed product. However, to produce an estimate of expected cost for a marketed product, we must allocate the costs of the unsuccessful projects to those 
that result in a marketed new product. The $R \& D$ process is lengthy, and as such it is important to know at what stage of development expenses occur. Viewed as an investment project, it is necessary to know both the amount of expenditures and the timing of these expenditures, since funds committed to $R \& D$ in advance of any returns from sales have both a direct and an opportunity cost. We used a unique database to estimate various cost parameters in the development process. Of particular concern is the estimation of the average pre-tax cost of new drug development, since we are interested in the resource costs of new drug development and how they have changed over time.

\subsection{Previous studies of the cost of pharmaceutical innovation}

A summary of early studies of the cost of drug development can be found in the authors' previous study (DiMasi et al., 1991) and in OTA (1993). In brief, the early studies were either based on a case study of a specific drug (usually ignoring the cost of failed projects) or relied on aggregate data. Since the $R \& D$ process often extends for a decade or more and the new drug development process often changes, it is difficult to estimate the cost of development from aggregated annual data. In contrast, the study by Hansen (1979) and the current authors' previous study (DiMasi et al., 1991) estimated development cost based on data supplied by firms for a representative sample of drug development efforts.

DiMasi et al. (1991) used data on self-originated new drugs to estimate the average cost of developing a new drug. They obtained data from 12 pharmaceutical firms on the research and development costs of 93 randomly selected new drugs that entered clinical trials between 1970 and 1982. From these data they estimated the average pre-tax out-of-pocket cost per approved drug to be US\$ 114 million (1987 dollars). Since these expenditures were spread out over nearly a dozen years, they capitalized these expenditures to the date of marketing approval using a 9\% discount rate. This yielded an estimate of US\$231 million (1987 dollars). Measured in constant dollars, this value is more than double that obtained by Hansen for an earlier sample. DiMasi et al. (1991) also found that the average cost of the first two phases of clinical trials doubled between the first and second half of their sample. This led to the expectation that development costs would be higher in future samples.

Based on an analysis by Myers and Shyam-Sunder performed for the OTA, the OTA (1993) report noted that the cost-of-capital for the industry was roughly $10 \%$ in the early 1980s. This is moderately higher than the $9 \%$ used by DiMasi et al. (1991). The OTA also recalculated the DiMasi et al. (1991) numbers using an interest rate that varied over the life of the R\&D cycle thereby raising the cost estimate by US\$ 100 million in 1990 dollars. ${ }^{1}$ The OTA presented both pre- and post-tax cost estimates.

\footnotetext{
1 The OTA applied a range of discount rates that varied with the time to marketing approval. They chose $14 \%$ for the earliest stage R\&D and 10\% for development just prior to approval, with rates in between that declined linearly with time in development. This approach was meant to capture the essence of the risk-return staircase perspective expressed by Myers and others, and discussed below. The methodology described in Myers and Howe (1997) is actually quite different, but the OTA technique yielded results that would not be much different (for the same distribution of costs) than what one would have obtained with the correct methodology (Myers and Howe, 1997, p. 33).
} 


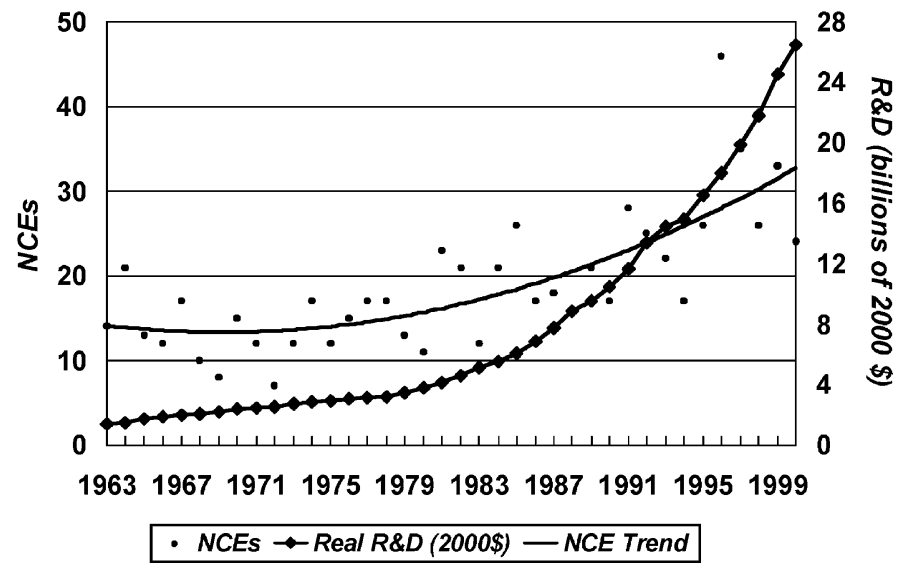

Fig. 1. Inflation-adjusted industry R\&D expenditures (2000 dollars) and US new chemical entity (NCE) approvals from 1963 to 2000. Source of data: PhRMA (2001) and Tufts CSDD Approved NCE Database.

\subsection{Aggregate data analyses}

There have been no recent comprehensive studies of the cost of developing new pharmaceuticals from synthesis to marketing approval based on actual project-level data. However, aggregate data and data on parameters of the drug development process suggest that R\&D costs have increased substantially since our earlier study. For example, the Pharmaceutical Research and Manufacturers of America (PhRMA, 2000) publishes an annual report on the R\&D expenditures of its member firms that shows a continuous increase in outlays well in excess of inflation. Reports on specific components of the R\&D process, such as the number of subjects in clinical trials (OTA, 1993; The Boston Consulting Group [BCG], 1993), also suggest an increase in the real cost of pharmaceutical innovation.

Published aggregate industry data suggest that R\&D costs have been increasing. Fig. 1 shows reported aggregate annual domestic prescription drug R\&D expenditures for members of the US pharmaceutical industry since 1963. The chart also shows the number of US new drug approvals by year. Given the much faster rate of growth of R\&D expenditures, data such as these suggest that $R \& D$ costs have increased over time. However, they cannot be conclusive or precise. For one matter, the drug development process is known to be very lengthy. Thus, new drug approvals today are associated with R\&D expenditures that were incurred many years prior. Ignoring the inherent lag structure underlying these data and simply dividing current R\&D expenditures by the number of new drug approvals will in general yield inaccurate estimates. ${ }^{2}$ Given a substantial increasing trend in R\&D

\footnotetext{
2 The estimates would also vary widely from year-to-year. For example, if we divided each year's real R\&D expenditures by that year's number of NCE approvals, we would obtain US\$ 1 billion for 2000, US\$743 million for 1999, US\$ 839 million for 1998, US\$ 568 million for 1997, US\$ 400 million for 1996, US\$ 635 million for 1995, and US\$ 878 million for 1994. While there is a general upward trend in such calculations, the year-to-year variability is not credible.
} 
expenditures, such calculations will result in greatly exaggerated estimates of out-of-pocket cost per approval.

Secondly, even properly lagged time series would tend to be imprecise if aggregate industry data were used as reported. The industry data include expenditures on improvements to existing products. Thus, they would overestimate pre-approval development costs. On the other hand, they also do not incorporate all of the R\&D on licensed-in drugs since firms or other organizations that are not members of the US trade association would have conducted some of the work. On that account the data would tend to underestimate costs. Therefore, $R \& D$ cost estimates based on project-level data are needed to assure a reasonable level of confidence in the accuracy of the results. We present results based on such data in this study.

The remainder of this paper is organized as follows. Section 2 describes the standard drug development paradigm, which serves as the structure through which the results are reported. Section 3 contains a description of the survey sample data and the population from which it was drawn. Section 4 describes the methodology used to derive R\&D cost estimates. We present our base case pre-marketing approval R\&D cost estimates in Section 5, as well as a comparison of our results with those of earlier studies to examine R\&D cost trends. Section 6 provides sensitivity analyses for key parameters. Section 7 focuses on some extensions of the base case analyses: estimates of clinical development costs for approved drugs by therapeutic significance, estimates of post-approval R\&D costs, and a tax analysis. Section 8 contains data and analyses that corroborate our results. Finally, we offer some conclusions in Section 9.

\section{The new drug development process}

New drug development can proceed along varied pathways for different compounds, but a development paradigm has been articulated that has long served well as a general model. The paradigm is explained in some detail elsewhere (DiMasi et al., 1991; US Food and Drug Administration [FDA], 1999). In outline form, the paradigm portrays new drug discovery and development as proceeding in a sequence of (possibly overlapping) phases. Discovery programs result in the synthesis of compounds that are tested in assays and animal models. It was not possible to disaggregate our data into discovery and preclinical development testing costs, ${ }^{3}$ so for the purposes of this study discovery and preclinical development costs are grouped and referred to as preclinical costs.

Clinical (human) testing typically proceeds through three successive phases. In phase I, a small number of usually healthy volunteers ${ }^{4}$ are tested to establish safe dosages and to gather information on the absorption, distribution, metabolic effects, excretion, and toxicity of the compound. To conduct clinical testing in the United States, a manufacturer must first

\footnotetext{
3 The reported basic research expenditures by firm were highly variable, and suggest that different firms may categorize their pre-human testing expenditures somewhat differently. Thus, we report pre-human testing costs in one figure.

${ }^{4}$ In some therapeutic areas, testing is initially done on patients who have the disease or condition for which the compound is intended to be a treatment. This is ordinarily true in the cancer and AIDS areas.
} 
file an investigational new drug application (IND) with the FDA. However, initiation of human testing can, and often does, occur first outside the United States.

Phase II trials are conducted with subjects who have the targeted disease or condition and are designed to obtain evidence on safety and preliminary data on efficacy. The number of subjects tested in this phase is larger than in phase I and may number in the hundreds. The final pre-approval clinical testing phase, phase III, typically consists of a number of large-scale (often multi-center) trials that are designed to firmly establish efficacy and to uncover side-effects that occur infrequently. The number of subjects in phase III trials for a compound can total in the thousands.

Once drug developers believe that they have enough evidence of safety and efficacy, they will compile the results of their testing in an application to regulatory authorities for marketing approval. In the United States, manufacturers submit a new drug application (NDA) or a biological license application (BLA) to the FDA for review and approval.

\section{Data}

Ten multinational pharmaceutical firms, including both foreign and US-owned firms, provided data through a confidential survey of their new drug R\&D costs. ${ }^{5}$ Data were collected on clinical phase costs for a randomly selected sample of the investigational drugs of the firms participating in the survey. ${ }^{6}$ The sample was taken from a Tufts Center for the Study of Drug Development (CSDD) database of investigational compounds. Cost and time data were also collected for expenditures on the kind of animal testing that often occurs concurrently with clinical trials. ${ }^{7}$ The compounds chosen were all self-originated; that is, their development up to initial regulatory marketing approval was conducted under the auspices of the surveyed firm. ${ }^{8}$ Licensed-in compounds were excluded because non-survey firms would have conducted portions of the R\&D. ${ }^{9}$

We also collected data from the cost survey participants on their aggregate annual pharmaceutical R\&D expenditures for the period 1980-1999. The firms reported on total annual $R \& D$ expenditures broken down by expenditures on self-originated new drugs, on licensed-in or otherwise acquired new drugs, and on already-approved drugs. Annual expenditures on self-originated new drugs were further decomposed into expenditures during the pre-human and clinical periods.

The National Institutes of Health (NIH) support through their own labs and through grants to researchers in academic and other non-profit institutions a substantial amount of research

\footnotetext{
${ }^{5}$ Using pharmaceutical sales to measure firm size, four of the survey firms are top 10 companies, another four are among the next 10 largest firms, and the remaining two are outside the top 20 (PJB, 2000).

6 A copy of the survey instrument is available upon request.

${ }^{7}$ Long-term teratogenicity and carcinogenicity testing may be conducted after the initiation of clinical trials.

8 This does not preclude situations in which the firm sponsors trials that are conducted by or in collaboration with a government agency, an individual or group in academia, a non-profit institute, or another firm.

${ }^{9}$ Large pharmaceutical firms much more often license-in than license-out new drug candidates. Firms that license-in compounds for further development pay a price for that right through up-front fees, milestone payments, and royalty arrangements.
} 
that expands fundamental knowledge about human biology (NIH, 2000; Scherer, 2000). This basic research sometimes results in leads that industrial researchers can capitalize on to assist them in discovering new therapeutic compounds. ${ }^{10}$ Some new compounds investigated by pharmaceutical firms, however, originated in government or academic labs. It is unclear whether the discovery and early development costs for such compounds are similar to those for compounds originating in industrial labs. These drugs, though, represent a very small portion of the total number developed. For example, NIH (2000) found that of 47 FDA-approved drugs that had reached at least US\$ 500 million in US sales in 1999, the government had direct or indirect use or ownership patent rights to only four of them. ${ }^{11}$ In addition, we used a Tufts CSDD database supplemented by commercial databases to determine that of the 284 new drugs approved in the United States from 1990 to $1999,{ }^{12}$ $93.3 \%$ originated from industrial sources (either from the sponsoring firm or from another firm from which the compound was licensed or otherwise acquired). Government sources accounted for $3.2 \%$ of these approvals and academia and other non-profits accounted for the other $3.5 \% .^{13}$

The survey firms accounted for $42 \%$ of pharmaceutical industry R\&D expenditures. ${ }^{14}$ The survey compounds were selected at random from data contained in the Tufts CSDD database of investigational compounds for the firms that agreed to participate in the R\&D cost survey. Of the 68 compounds chosen, 61 are small molecule chemical entities, four are recombinant proteins, two are monoclonal antibodies, and one is a vaccine. Initial human testing anywhere in the world for these compounds occurred during the period 1983-1994. Development costs were obtained through $2000 .{ }^{15}$

\footnotetext{
10 The NIH also supports the development of research tools that drug developers find useful. In addition, it funds training for many scientists, some of whom eventually are employed in the industrial sector.

11 The four drugs were developed in part through the use of NIH-funded patented technologies. Three of the four products are recombinant proteins, with two being the same drug produced by two different companies. Each of the relevant patented technologies was developed at academic or non-profit institutions with financial support from the NIH.

12 The definition of a new drug used for this analysis is a therapeutic new molecular entity approved by the FDA's Center for Drug Evaluation and Research.

13 The proportion of investigational drugs that derive from industrial sources is likely to be even higher, since acquired drugs have higher clinical approval success rates than do self-originated drugs (DiMasi, 2001b). Our cost survey firms were less reliant on licensing-in drugs from non-industrial sources than were firms as a whole; $98.8 \%$ of their new drug approvals during 1990-1999 were from industrial sources. DiMasi (2000) found markedly greater market entry of small niche pharmaceutical firms in the 1990s relative to earlier periods as measured by sponsorship of new chemical entity (NCE) approvals. A disproportionate share of the approvals obtained by these new entrants was for drugs that originated in academia.

14 The data used were aggregate firm pharmaceutical R\&D expenditures for the cost survey firms, as reported on our questionnaire, in comparison to PhRMA member firm R\&D expenditures (1994-1997) on ethical pharmaceuticals, adjusted to global expenditure levels (PhRMA, 2001).

15 Surveys were sent to 24 firms (some of whom have since merged). Twelve firms responded that they would participate in some form. The data that two firms ultimately provided were not useable. The 10 firms from which we used data provided information on 76 compounds. However, the data for eight of these compounds were not sufficiently comprehensive to use. The firms that did not participate in the survey cited a number of reasons for not doing so. The reasons included the extra demands that the transition effects of a relatively recent merger were placing on their relevant personnel, the time and expense of retrieving archival records in the manner required by the study, and difficulties in gathering the relevant data in a uniform manner because their accounting systems had changed significantly over the study period.
} 
We selected a stratified random sample of investigational compounds. Stratification was based on the time elapsed since the origination of clinical trials and the current status of that testing. Reported costs were weighted to reflect the characteristics of the population, so that knowledge of the population from which the sample was drawn was needed. The population is composed of all investigational compounds in the Tufts CSDD investigational drug database that met study criteria: the compounds were self-originated and first tested in humans anywhere in the world from 1983 to 1994, and we had the information necessary to classify them according our strata. We found 538 investigational drugs that met these criteria. Of these compounds, $82(15.2 \%)$ have been approved for marketing, $9(1.7 \%)$ had NDAs or BLAs that were submitted and are still active, $5(0.9 \%)$ had NDAs or BLAs submitted but abandoned, $227(42.2 \%)$ were terminated in 4 years or less from the initiation of clinical trials, $172(32.0 \%)$ were terminated more than 4 years after the start of clinical testing, and $43(8.0 \%)$ were still in active testing as of the most recent check (31 March 2001).

Some firms were not able to provide full phase cost data for every new drug sampled. For example, phase I cost data were available for 66 of the 68 new drugs. However, we had some phase cost data for every drug in the sample. In addition, five compounds were still active at the time of the study. For these drugs it is possible that there will be some future costs for the drug's most recent phase. Thus, for this reason our cost estimates may be somewhat conservative. However, given the small number of drugs in this category and the fact that the impact would be on only one phase for each of these drugs, our overall cost estimates are not likely to be materially affected.

\section{Methodology for estimating new drug development costs}

The approach that we use to estimate development costs is similar to that described in our earlier work (DiMasi et al., 1991). We will outline here the general methodology for developing an overall cost estimate. In describing the approach, it will be clear that cost estimates for important components of the drug development process will also be derived along the way.

The survey sample was stratified to reduce sampling error. Results from previous analyses suggested that the variability of drug costs tends to increase with the development phase or the amount of time that a drug spends in testing (Hansen, 1979; DiMasi et al., 1991). Costs for successful drugs (i.e. those that achieve regulatory approval) also tend to be higher and more variable than those for drug failures. Thus, we based our strata on the length of time that failed compounds were in clinical testing and whether or not a compound had reached the stage in which an application for marketing approval had been filed with the FDA. ${ }^{16}$

\footnotetext{
16 Specifically, we used four strata: compounds that failed in 4 years or less of clinical testing; compounds that failed after more than 4 years had elapsed from initial human testing; compounds for which an NDA or a BLA had been submitted to the FDA; and compounds that were still in active testing (as of 30 March 2001). Compounds for which an application for marketing approval had been submitted or which had been abandoned after lengthy testing were deliberately oversampled. The reported sample values were then weighted, where the weights were determined so that the sample perfectly reflects the population in terms of the four strata.
} 


\subsection{Expected costs in the clinical period}

Since new drug development is a risky process, with many compounds failing for every one that succeeds, it is necessary to analyze costs in expected value terms. The total clinical period cost for an individual drug can be viewed as the realization of a random variable, $c$. Given that it is not certain that development of a randomly selected investigational compound will proceed to a given phase, we may define expected clinical costs for a randomly selected investigational drug to be $C=E(c)=p_{\mathrm{I}} \mu_{\mathrm{I} \mid \mathrm{e}}+p_{\mathrm{II}} \mu_{\mathrm{II} \mid \mathrm{e}}+p_{\mathrm{III}} \mu_{\mathrm{III} \mid \mathrm{e}}+p_{\mathrm{A}} \mu_{\mathrm{A} \mid \mathrm{e}}$, where $p_{\mathrm{I}}, p_{\mathrm{II}}$, and $p_{\text {III }}$, are the probabilities that a randomly selected investigational compound will enter phases I-III, respectively, $p_{\mathrm{A}}$ the probability that long-term animal testing will be conducted during the clinical trial period, and the $\mu$ 's are conditional expectations. Specifically, $\mu_{\mathrm{I} \mid \mathrm{e}}$, $\mu_{\mathrm{II} \mid \mathrm{e}}, \mu_{\mathrm{III} \mid \mathrm{e}}$, and $\mu_{\mathrm{A} \mid \mathrm{e}}$ are the population mean costs for drugs that enter phases I-III, and clinical period long-term animal testing, respectively.

Weighted mean phase costs derived from the cost survey data were used to estimate the conditional expectations. A description of how the probabilities were estimated is presented in the next section. Assuming that the estimated mean phase costs and success probabilities are stochastically independent, the estimated expected value is an unbiased estimate of the population expected value.

\subsection{Clinical success and phase attrition rates}

An overall clinical approval success rate is the probability that a compound that enters the clinical testing pipeline will eventually be approved for marketing. Attrition rates describe the rate at which investigational drugs fall out of testing in the various clinical phases. A phase success rate is the probability that a drug will attain marketing approval if it enters the given phase. A phase transition probability is the likelihood that an investigational drug will proceed in testing from one phase to the next. All of these probabilities can be estimated from data in the Tufts CSDD database of investigational drugs from which our survey sample was drawn.

The clinical approval success rate was estimated using a two-stage statistical estimation process that has been described in detail elsewhere (DiMasi et al., 1991; DiMasi, 2001b). The data used here consist of the investigational drugs in the Tufts CSDD database that were first tested in humans anywhere in the world from 1983 to 1994, with information on their status (approval or research abandonment) obtained through early 2001. Given that some of these investigational drugs were still in active testing at the end of the study period, some of the data are right-censored. Survival analysis can be applied in such a situation, where survival indicates that a drug has not reached its ultimate fate (either approval or abandonment).

The Tufts CSDD database of investigational compounds contains information on the latest phase that an abandoned compound was in when it was terminated. These data were used to determine the distribution of research terminations by phases. ${ }^{17}$ These results,

\footnotetext{
17 A small proportion of the compounds in the database were either still in clinical development $(8.0 \%)$ or had an NDA or BLA filed but not yet approved (1.7\%). For those drugs in these groups that will eventually fail, their abandonment will tend to occur in later testing phases. To deal with the potential bias in the estimated distribution of research terminations that would result from using just those compounds that had been abandoned by the end of
} 
together with the estimated overall clinical approval success rate were used to provide estimates of the probability that an investigational drug will enter a given phase, phase attrition rates, and phase transition probabilities. The estimated overall clinical approval success rate and the probabilities of entering various phases provide results with which estimates can be derived that include the cost of drugs that fail to make it through the development process. Specifically, we use the probabilities of entering a phase to estimate the expected out-of-pocket clinical cost per investigational drug. Adding the out-of-pocket preclinical cost estimate described below yields an estimate of total out-of-pocket cost per investigational drug. Dividing this estimate by the overall clinical success rate yields our estimate of out-of-pocket cost per approved drug.

\subsection{Out-of-pocket discovery and preclinical development costs}

Many costs incurred prior to clinical testing cannot be attributed to specific compounds. Thus, aggregate level data at the firm level were used to impute costs per drug for $R \& D$ incurred prior to human testing. Specifically, time series data for each surveyed firm on spending on pre-human R\&D and on human testing for 1980-1999 were obtained, and a ratio of pre-human $R \& D$ expenditures to human testing expenditures was determined based on an appropriate lag structure (on average, pre-human R\&D expenditures should occur years prior to the associated human testing costs). This ratio was then multiplied by an estimate of out-of-pocket clinical cost per drug, which is based on the project-level data, to yield an estimate of the pre-human R\&D cost per new drug. ${ }^{18}$

\subsection{Capitalized costs: development times and the cost-of-capital}

Given that drug development is a very lengthy process, the full cost of drug development should depend significantly on the timing of investment and returns. Full cost estimates require a capitalization of the stream of out-of-pocket costs to some point (the date of marketing approval is the standard). To do so, one needs a timeline for a representative drug. The timeline is constructed from information on average phase lengths and the average gaps and overlaps between successive phases in a Tufts CSDD database of approved new drugs and in our cost survey. The periods considered are the time from synthesis to human testing,

the study period, we statistically predicted whether each open compound (still in clinical testing) would eventually fail. To do so, we evaluated an estimated conditional approval probability function (probit specification) at the number of years that the compound had been in testing. Failures were taken to occur in the latest reported testing phase. Summing the failure probabilities by phase gives us additional terminations by phase. The distribution of research terminations by phase was adjusted accordingly. Compounds that had reached the NDA/BLA phase likely have a very high probability of success. DiMasi (2001a) found very high approval rates for NDA submissions, with an increasing trend. To be conservative, we assumed that all of the compounds with still active NDAs or BLAs would be approved. This leads to lower cost estimates than would be the case if the same procedure for determining failure that was used for compounds still in testing had been used instead. However, given the very small number of compounds in the active NDA/BLA category, the impact on the results is trivial.

18 The survey firms were asked to indicate whether charges for corporate overhead unrelated to R\&D appear in their R\&D budget data, and, if so, to estimate what share of expenditures they represent. Two firms reported that they did, and so we reduced the aggregate and project-level data for those firms according to their reported shares for corporate overhead. 
the three clinical phases, an animal testing phase concurrent with clinical development, and the length of time from submission of an NDA/BLA to NDA/BLA approval.

Whereas the survey data cover a development period that yielded approvals from 1990 to 2001, the bulk of the approvals occurred in the mid to late 1990s. Thus, we estimated phase lengths, gaps, and overlaps for self-originated new drugs that were approved during 1992-1999. The data included therapeutic biopharmaceuticals, as well as small molecule drugs. ${ }^{19}$ Once a timeline is established and out-of-pocket costs are allocated over that timeline, the expenditures must be capitalized at an appropriate discount rate. The discount rate should be the expected return that investors forego during development when they invest in pharmaceutical R\&D instead of an equally risky portfolio of financial securities. Empirically, such a discount rate can be determined by examining stock market returns and debt-equity ratios for a representative sample of pharmaceutical firms over a relevant period. The resulting discount rate is an average company cost-of-capital. We describe the estimation of our base case cost-of-capital in Section 5.2 below.

We assume that phase costs are distributed uniformly over the phase length and apply continuous compounding to the point of marketing approval. Summing these capitalized preclinical and clinical capitalized cost estimates yields a total capitalized cost per investigational drug. Dividing by the overall clinical success rate results in our estimate of the total capitalized cost per approved new drug. This estimate is a measure of the full resource cost needed, on average, for industry to discover and develop a new drug to the point of marketing approval.

\section{Base case $R \& D$ cost estimates}

\subsection{Out-of-pocket clinical cost per investigational drug}

Given the method of weighting reported costs as described in Section 4, weighted means, medians, and standard deviations were calculated and are presented in Table $1 .{ }^{20}$ Mean

\footnotetext{
19 The percentage of all self-originated new compound approvals that are for biopharmaceuticals is substantially larger than is the proportion of either self-originated approvals or investigational compounds that are for biopharmaceuticals in the Tufts CSDD investigational drug database. The survey firms in this database are predominantly traditional pharmaceutical firms. Thus, we estimate clinical phase lengths and approval phase times for new chemical entities and biopharmaceuticals separately and compute a weighted average of the mean phase lengths, where the weights are the shares of self-originated investigational compounds in the Tufts CSDD database for each of these compound types.

${ }^{20}$ For five of the sample drugs, the survey firms were not able to disaggregate costs for two successive clinical phases (i.e. either phases I and II or phases II and III). We developed a two-stage iterative process for imputing phase costs for these drugs. To illustrate, suppose that the firm combined phases II and III costs for a specific drug. For a year during which the drug was in both phase II and III testing, let $m_{\mathrm{II}}=$ number of months the drug was in phase II only, $m_{\mathrm{III}}=$ number of months the drug was in phase III only, $m_{0}=$ number of months the drug was in both phases, $T=$ total clinical phase cost for the drug during the year, and $\mathrm{cr}=$ ratio of weighted monthly phase III to phase II cost for drugs where phase costs were disaggregated. Imputed phase II cost, $x_{\mathrm{II}}$, can then be defined as $x_{\mathrm{II}}=\left(m_{\mathrm{II}}+\mathrm{cr} \cdot m_{0}\right) T /\left(m_{\mathrm{II}}+\mathrm{cr} \cdot m_{\mathrm{III}}+[1+\mathrm{cr}] \cdot m_{0}\right)$. Imputed phase III cost is determined as $x_{\mathrm{III}}=\mathrm{cr} \cdot x_{\mathrm{III}}$. The same approach was used when phase I and II costs were combined by the responding firm. To further refine the results, we included the imputed costs for the five drugs from the first stage and recomputed the phase cost ratios to determine second stage values for the imputed costs. The results for imputed costs barely changed between the first and the second iterations.
} 
Table 1

Average out-of-pocket clinical period costs for investigational compounds (in millions of 2000 dollars) $^{\mathrm{a}}$

\begin{tabular}{lcccccc}
\hline Testing phase & Mean cost & Median cost & $\begin{array}{l}\text { Standard } \\
\text { deviation }\end{array}$ & $N^{\mathrm{b}}$ & $\begin{array}{l}\text { Probability of } \\
\text { entering phase (\%) }\end{array}$ & Expected cost \\
\hline Phase I & 15.2 & 13.9 & 12.8 & 66 & 100.0 & 15.2 \\
Phase II & 23.5 & 17.0 & 22.1 & 53 & 71.0 & 16.7 \\
Phase III & 86.3 & 62.0 & 60.6 & 33 & 31.4 & 27.1 \\
Long-term animal & 5.2 & 3.1 & 4.8 & 20 & 31.4 & 60.6 \\
Total & & & & & & 6 \\
\hline
\end{tabular}

${ }^{a}$ All costs were deflated using the GDP Implicit Price Deflator. Weighted values were used in calculating means, medians, and standard deviations.

${ }^{\mathrm{b}} N$ : number of compounds with full cost data for the phase.

cost per investigational drug entering a phase increases substantially by clinical phase, particularly for phase III, which is typically characterized by large-scale trials. In comparison to the previous study (DiMasi et al., 1991), mean phase I cost is moderately higher relative to the other phases. While the ratio of mean phase III cost to mean phase I cost was 6.0 for the previous study, it was 5.7 here. Similarly, the ratio of mean phase II to phase I cost was 1.9 for the earlier study, but was 1.5 for this study. The higher relative phase I cost is consistent with other data that indicate that the growth in the number of procedures per patient was much greater for phase I than for the other phases during the 1990s. ${ }^{21}$

Mean clinical phase costs increased approximately five-fold in real terms between the studies. However, in comparison, long-term animal testing costs incurred during the clinical period increased by only $60 \%$. Thus, increases in out-of-pocket clinical period costs were driven heavily by increases in human trial, as opposed to animal testing, costs. This suggests that preclinical animal studies may also have not increased at anywhere near the same rate as have clinical trial costs. The results also indicate that development costs have become more uniform across drugs.

This is indicated by two comparisons with the results from the previous study. The ratio of mean to median phase cost decreased $50 \%$ for phase I, $22 \%$ for phase II, and $13 \%$ for phase III for the present study in comparison to the earlier study. Thus, the data are less skewed. The coefficients of variation for the phases also declined. They are $60 \%$ lower for phase I, 29\% lower for phase II, and 36\% lower for phase III.

Estimates of the probability that an investigational drug will enter a phase were obtained from statistical analysis of information in the Tufts CSDD database of investigational compounds for drugs that met study criteria. They are shown in Table 1 and are used to obtain the expected phase costs in the last column. The probabilities are lower in comparison to the previous study (75.0\% for phase II, 36.3\% for phase III, and 56.1\% for long-term animal testing). Lower probabilities of entering a phase will, other things being equal, result in lower expected costs. Thus, while the mean phase costs for drugs entering a phase are

\footnotetext{
21 One of the authors obtained data from DataEdge, LLC on the number of procedures administered to patients by phase from 1990 to 1997 . The data were based on information in the clinical trial grants of a very large number of pharmaceutical firms. During this period, the number of procedures per patient increased $27 \%$ for phase III, $90 \%$ for phase II, and $120 \%$ for phase I.
} 
approximately five times higher in this study, the expected cost per investigational drug is only four times higher.

Alternative probability estimates for the same data make clear how reductions in drug development risks hold down development costs. Our earlier study showed proportionately fewer failures in phase I (32.5\% versus $37.0 \%)$ and proportionately more failures in phase III (17.1\% versus $12.6 \%)$; the share for phase II was identical. Thus, given a similar overall clinical success rate, the evidence suggests that over time firms became better able to weed out failures (clinical or economic) early in the process. A similar scenario holds when we examine phase transition probabilities. In the earlier study, a larger percentage of investigational drugs made it to phase II (75.0\% versus $71.0 \%)$ and a smaller percentage proceeded from phase III to marketing approval (63.5\% versus $68.5 \%)$.

\subsection{Cost-of-capital estimates}

In our earlier paper (DiMasi et al., 1991), we employed a 9\% real cost-of-capital based on a capital asset pricing model (CAPM) analysis for a representative group of pharmaceutical firms during the 1970s and early 1980s. A real rather than a nominal cost-of-capital is appropriate in our analysis since $\mathrm{R} \& \mathrm{D}$ costs are expressed in constant 2000 dollars. The real cost-of-capital in pharmaceuticals has increased since the mid-1980s primarily as a result of higher real rates of return required by holders of equity capital during the 1990s.

In the present analysis, we compute a weighted cost-of-capital for each firm in a representative group of pharmaceutical firms for the 1980s and 1990s, where the weights are based on the firm's market value of debt and equity. For most major pharmaceutical firms, debt securities account for less than $10 \%$ of market valuation, so that the equity cost-of-capital component is the dominant element of the weighted cost-of-capital for this industry. At the request of the OTA, Myers and Shyam-Sunder (1996) estimated the cost-of-capital for the pharmaceutical industry during the 1970s and 1980s using a standard CAPM approach. Their methodology is the basis for our updated analysis.

In our R\&D cost analysis we have a sample of new drugs that began clinical trials in the mid-1980s through the early 1990s, and which have an average market introduction point in the late 1990s. Hence a relevant time period for our cost-of-capital measure is 1985-2000. Accordingly, we estimated the cost-of-capital at roughly 5-year intervals beginning in January 1985 and ending in January 2000. The results of our analysis are summarized in Table 2.

The nominal cost-of-capital in 1985 and 1990 are based on Myers and Shyam-Sunder's analysis for the OTA. The 1994 value is from Myers and Howe (1997). The 2000 nominal cost-of-capital (COC) value is based on our own estimation, employing a sample of firm and data sources comparable to those used in the prior work of Myers and colleagues. As can be seen in Table 2, the nominal cost-of-capital for pharmaceutical firms has remained relatively stable in this period in the range of $14-16 \%$, with a mean of approximately $15 \% .^{22}$

\footnotetext{
22 We undertook an informal survey of major pharmaceutical firms in mid-2001 with respect to the hurdle rate that they used in their R\&D investment decisions. This survey of six firms yielded (nominal) hurdle rates from 13.5 to over $20 \%$. This indicates that a $15 \%$ nominal COC rate is within the range of hurdle rates utilized by major pharmaceutical firms for their actual R\&D investments.
} 
Table 2

Nominal and real cost-of-capital (COC) for the pharmaceutical industry, 1985-2000

\begin{tabular}{lrrrr}
\hline & 1985 & 1990 & 1994 & 2000 \\
\hline${\text { Nominal COC }(\%)^{\mathrm{a}}}_{\text {Inflation rate }(\%)^{\mathrm{b}}}$ & 16.1 & 15.1 & 14.2 & 15.0 \\
Real COC $(\%)$ & 5.4 & 4.5 & 3.1 & 3.1 \\
\hline
\end{tabular}

a The nominal values for 1985 and 1990 are based on Myers and Shyam-Sunder (1996). The nominal value for 1994 is taken from Myers and Howe (1997). The 2000 nominal value is based on our own computations using comparable samples and data sources.

b The inflation rate for 1985 is taken from Myers and Howe (1997), the rate for 1990 is a 5-year average centered on January 1990 and is based on the CPI-U, the rate for 1994 and 2000 is the long-term inflation rate from 1926 to 2000 (Ibbotson Associates, 2001, p. 17).

To obtain a real cost-of-capital, we subtracted the expected rate of inflation from the nominal cost-of-capital. For this purpose, Myers and Shyam-Sunder (1996) used the expected rate of inflation from a special consumer survey performed in the 1980s. We also used this value in Table 2 for the 1985 period. For 1990 we utilized a 5-year moving average of actual inflation rates centered around the year in question to estimate expected rates of inflation. For 1994 and 2000 we used the long-term inflation rate (1926-2000) in Ibbotson and Associates (2001) of $3.1 \%$ to compute the values in Table $2 .{ }^{23}$

The real cost-of-capital for the pharmaceutical industry over this period, using the CAPM model, varies from 10.6 to $12.0 \%$. The mean cost-of-capital in this period was just over $11 \%$. Hence, $11 \%$ is the baseline value that we employed in our R\&D cost estimates. ${ }^{24}$ However, as in prior studies, we did sensitivity analysis around this value in order to determine how our baseline R\&D cost estimates are affected by changes in the cost-of-capital.

\subsection{Capitalized clinical cost per investigational drug}

To calculate opportunity cost for clinical period expenditures we estimated average phase lengths and average gaps or overlaps between successive clinical phases. Mean phase lengths and mean times between successive phases are shown in Table 3. The time between the start of clinical testing and submission of an NDA or BLA with the FDA was estimated to be 72.1 months, which is 3.5 months longer than the same period estimated in the previous study. However, the time from the start of clinical testing to marketing approval in our timeline for a representative drug averaged 90.3 months for the current study, compared to

\footnotetext{
23 Inflation rates were particularly low in the 1990s, and 5-year moving averages were below the long-term rate. Since the 1990 s represented a marked change in the inflation rate from earlier decades, and inflationary expectations may not adjust immediately to the new experience, we used the long-term inflation rate rather than 5 -year moving averages for this period.

24 This yields conservative estimates of the cost of capital from several perspectives. One important point concerns the fact that many major pharmaceutical firms have large positive cash balances and are actually net lenders rather than net borrowers (i.e. they have a negative debt ratio). Incorporating this point into their CAPM analysis for January, 1990, causes the estimated nominal value of the cost of capital to increase by almost a full percentage point (see Myers and Shyam-Sunder, 1996, p. 223). In addition, as noted in footnote 4, many firms appear to use higher costs of capital in their R\&D investment decisions than what emerges from this CAPM analysis.
} 
Table 3

Average phase times and clinical period capitalized costs for investigational compounds (in millions of 2000 dollars $)^{\mathrm{a}}$

\begin{tabular}{|c|c|c|c|c|}
\hline Testing phase & $\begin{array}{l}\text { Mean phase } \\
\text { length }\end{array}$ & $\begin{array}{l}\text { Mean time to } \\
\text { next phase }\end{array}$ & $\begin{array}{l}\text { Capitalized mean } \\
\text { phase } \operatorname{cost}^{\mathrm{b}, \mathrm{c}}\end{array}$ & $\begin{array}{l}\text { Capitalized expected } \\
\text { phase cost } \mathrm{c}^{\mathrm{b}, \mathrm{c}}\end{array}$ \\
\hline Phase I & 21.6 & 12.3 & 30.5 & 30.5 \\
\hline Phase II & 25.7 & 26.0 & 41.6 & 29.5 \\
\hline Phase III & 30.5 & 33.8 & 119.2 & 37.4 \\
\hline Long-term animal & 36.5 & - & 9.5 & 3.0 \\
\hline Total & & & & 100.4 \\
\hline
\end{tabular}

\footnotetext{
${ }^{a}$ All costs were deflated using the GDP Implicit Price Deflator. Weighted values were used in calculating means, medians, and standard deviations for costs and phase times. Phase times are given in months.

$\mathrm{b}$ The NDA approval phase was estimated to be 18.2 months. Animal testing was estimated to begin 4.2 months after the initiation of phase I.

${ }^{\mathrm{c}}$ Costs were capitalized at an $11 \%$ real discount rate.
}

98.9 months for the earlier study. The difference is accounted for by the much shorter FDA approval times in the mid to late 1990s that were associated with the implementation of the Prescription Drug Use Fee Act of 1992. While the approval phase averaged 30.3 months for the earlier paper's study period, that phase averaged only 18.2 months for drugs covered by the current study.

Other things being equal, the observed shorter times from clinical testing to approval yield lower capitalized costs relative to out-of-pocket costs. However, the discount rate that we used for the current study is also higher than for the previous study (11\% versus $9 \%)$. The two effects work in offsetting ways. On net, there was very little difference between the studies in the ratio of mean capitalized to out-of-pocket cost for the individual clinical phases. ${ }^{25}$

\subsection{Clinical cost per approved new drug}

Although average cost estimates for investigational drugs are interesting in their own right, we are mainly interested in developing estimates of cost per approved new drug. To do so, we need an overall clinical approval success rate. Our statistical analysis of compounds in the Tufts CSDD database of investigational drugs that met study criteria yielded a predicted final clinical success rate of $21.5 \%$. Applying this success rate to our estimates of out-of-pocket and capitalized costs per investigational drug results in estimates of cost per approved new drug that link the cost of drug failures to the successes.

Aggregating across phases, we find that the out-of-pocket clinical period cost per approved new drug is US\$282 million and the capitalized clinical period cost per approved new drug is US\$ 467 million. These costs are more than four-fold higher than those we found in our previous study.

\footnotetext{
25 The ratios of capitalized to out-of-pocket cost for the earlier study were 1.9, 1.7, 1.4, and 1.6 for phases I-III, and animal testing, respectively. For this study, we found the ratios to be 2.0, 1.8, 1.3, and 1.8 for phases I-III, and animal testing, respectively.
} 


\subsection{Preclinical out-of-pocket and capitalized costs per approved drug}

The preclinical period, as defined here, includes discovery research as well as preclinical development. As noted above, not all costs during this period can be allocated to specific compounds. To deal with this issue, we analyzed aggregate annual firm expenditures on self-originated new drugs by the preclinical and clinical periods. We gathered data on aggregate expenditures for these periods from survey firms for 1980-1999. Both times series tended to increase over time in real terms. Given this outcome, and the fact that the clinical expenditures in 1 year will be associated with preclinical expenditures that occurred years earlier, the ratio of total preclinical expenditures to total R\&D (preclinical plus clinical) expenditures over the study period will yield an overestimate of the share of total cost per new drug that is accounted for by the preclinical period. To accurately estimate this share we built in a lag structure that associates preclinical expenditures with clinical expenditures incurred some time later. Using data in the Tufts CSDD database of approved drugs, we estimated the average time from synthesis of a compound to initial human testing for self-originated drugs to be 52.0 months. Our analysis of clinical phase lengths and phase gaps and overlaps indicates a period of 68.8 months over which clinical period development costs are incurred. We approximate the lag between preclinical and clinical expenditures for a representative new drug as the time between the midpoints of each period. This yields a lag of 60.4 months, or approximately 5 years. Thus, we used a 5-year lag in analyzing the aggregate expenditure data. Doing so resulted in a preclinical to total R\&D expenditure ratio of $30 \%$. This share was applied to our clinical cost estimates to determine corresponding preclinical cost estimates. Given the estimates of out-of-pocket and capitalized clinical cost per approved new drug noted in Section 5.4, we can infer preclinical out-of-pocket and capitalized costs per approved new drug of US\$ 121 and 335 million, respectively. The results are very robust to different values for the length of the lag structure. For example, if we assume a lag of 4 years instead of 5 years, then out-of-pocket preclinical costs would be $9.8 \%$ higher. Alternatively, if we assume a 6-year lag, then out-of-pocket preclinical costs would be $9.3 \%$ lower.

\subsection{Total capitalized cost per approved drug}

Our full cost estimate is the sum of our preclinical and clinical period cost estimates. Our base case out-of-pocket cost per approved new drug is US\$ 403 million, while our fully capitalized total cost estimate is US\$ 802 million. Time costs, thus, account for $50 \%$ of total cost. This share is nearly identical to one that we found in our previous study $(51 \%)$. This is the case even though the time cost shares for both the clinical and preclinical periods are somewhat higher for this study. The explanation for this seeming inconsistency is that time costs are relatively greater for preclinical expenditures since they are incurred earlier in the process, but the preclinical share of total costs is lower for the present study.

\subsection{Trends in R\&D costs}

Fig. 2 presents the primary results (capitalized preclinical, clinical, and total cost per approved new drug) for the previous two studies and for our current study. In inflation-adjusted 


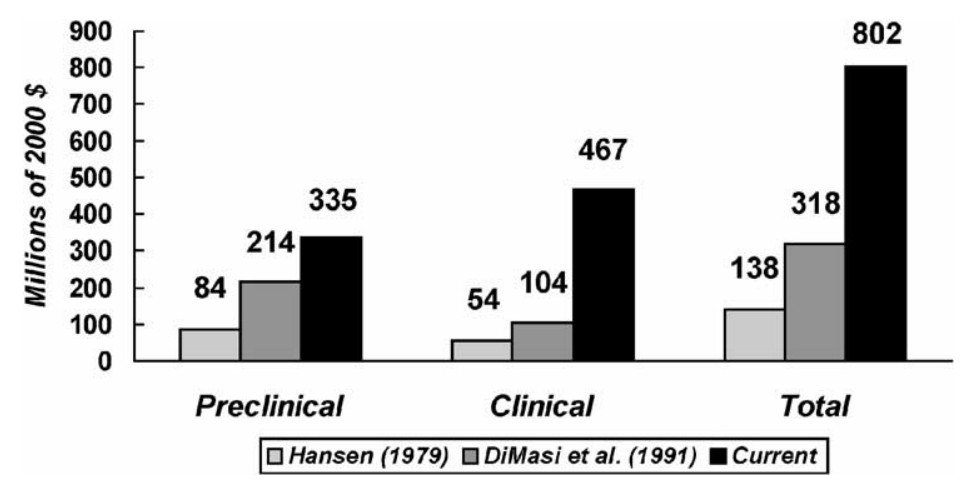

Fig. 2. Trends in capitalized preclinical, clinical and total cost per approved new drug.

terms, total capitalized cost was 2.3 times higher for the previous study in comparison to the first study. Real total capitalized cost per approved new drug for the current study is 2.5 times higher than for the previous study. However, the samples for these studies include drugs that entered clinical testing over periods that are not uniformly dispersed. In addition, while the samples were chosen on the basis of when drugs entered clinical testing, changes over time in the average length of the development process make ascribing differences in the study periods according to the year of first human testing problematic. An alternative is to determine an average approval date for drugs in each study's sample and use the differences in these dates to define the time differences between the studies. This will allow us to determine annual cost growth rates between successive studies.

Drugs in the current study sample obtained FDA marketing approval from 1990 to 2001, with the vast majority of the approvals occurring between 1992 and 2000. The mean and median approval date for drugs in the current study's sample was in early 1997. For the previous study, we reported that the average approval date was in early 1984 . Thus, we used 13 years as the relevant time span between the studies and calculated compound annual rates of growth between the two studies accordingly.

Hansen (1979) did not report an average approval date; however, we can infer a period difference by noting the sample selection criteria and the difference in development times between that study and the DiMasi et al. (1991) study. The sample selection criteria for DiMasi et al. (1991) involved a 7-year shift in initial clinical testing relative to Hansen (1979). However, the estimated time from the start of clinical testing to marketing approval was 2.3 years longer for the DiMasi et al. (1991) study. Thus, we use 9.3 years as the difference between the study periods for these two studies.

Using these period differences, we found that the compound annual growth rates in total out-of-pocket cost per approved drug were quite similar across the studies (Table 4). The growth in total costs, however, masks substantial differences in growth rates for the preclinical and clinical periods. While out-of-pocket preclinical expenditures continued to grow in real terms, its growth rate for the current study relative to the previous one declined by two-thirds in comparison to the growth rate for the first two studies. Conversely, the growth rate for clinical period expenditures approximately doubled for the two most recent studies. 
Table 4

Compound annual growth rates in out-of-pocket and capitalized inflation-adjusted costs per approved new drug ${ }^{\mathrm{a}}$

\begin{tabular}{lllllllll}
\hline Period & \multicolumn{2}{l}{ Out-of-pocket } & & & \multicolumn{2}{l}{ Capitalized } \\
\cline { 2 - 3 } & Preclinical (\%) & Clinical (\%) & Total (\%) & & Preclinical (\%) & Clinical (\%) & Total (\%) \\
\hline $1970-1980$ & 7.8 & 6.1 & 7.0 & & 10.6 & 7.3 & 9.4 \\
$1980-1990$ & 2.3 & 11.8 & 7.6 & & 3.5 & 12.2 & 7.4
\end{tabular}

${ }^{a}$ Costs for the 1970s approvals are from Hansen (1979), costs for the 1980s approvals are from DiMasi et al. (1991), and costs for the 1990s approvals are from the current study.

Annual growth rates for capitalized costs are also shown in Table 4. The results show a substantially higher growth rate for clinical costs for the two most recent analyses. However, while the growth rate for total out-of-pocket cost per approved drug was slightly greater for the two most recent studies, the growth rate in total capitalized cost was two percentage points higher between the first and second study than between the second and third. This is so, despite the fact that the discount rate increased one percentage point between the first two studies, but two percentage points between the last two. The growth rate in capitalized costs, however, is driven more by the fact that preclinical costs have a lower share of total out-of-pocket costs in the current study than in the previous studies, and time costs are necessarily proportionately more important for preclinical than for clinical expenditures.

\section{Sensitivity analysis}

\subsection{Effects of parameter changes}

We undertook sensitivity analyses for several of the key parameters that underlie the cost estimates. Fig. 3 shows how preclinical, clinical, and total capitalized costs would vary by discount rate at half-percentage point intervals. The values for a zero percent discount rate are out-of-pocket costs. In the neighborhood of our base case discount rate (11\%), clinical cost changes by about US\$10 million, preclinical cost changes by about US\$15 million,

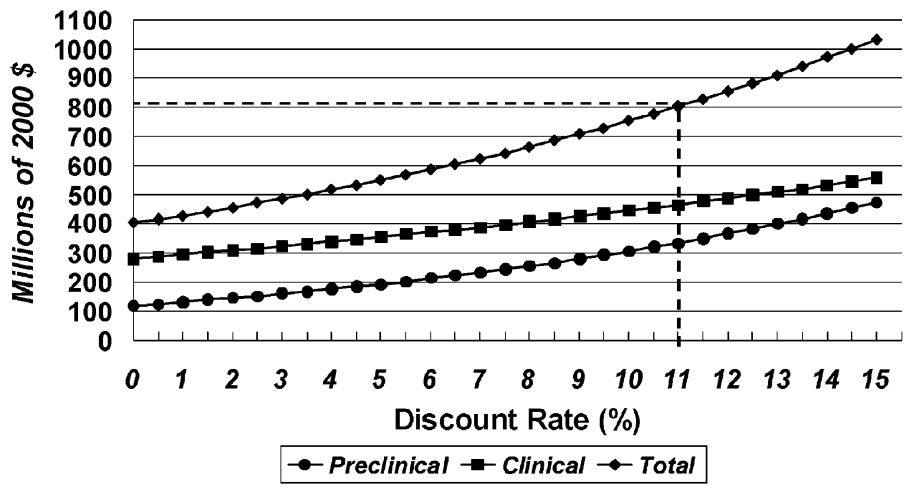

Fig. 3. Capitalized preclinical, clinical, and total costs per approved new drug by discount rate. 
and total cost changes by about US\$ 25 million for every half of one percent shift in the discount rate. In our previous study, the base case discount rate was $9 \%$. At a $9 \%$ discount rate, total capitalized cost here is US\$ 707 million, or $11.8 \%$ less than our base case result. The results in section 5.3 provide some support for an even higher discount rate than our base case value. At a $12 \%$ discount rate, total capitalized cost per approved new drug is US\$ 855 million, or $6.6 \%$ higher than our base case result.

The clinical approval success rate is another key parameter. We analyzed the effects of an approximate $10 \%$ change in the success rate at various discount rates. A higher success rate has a somewhat smaller impact on total cost than does a correspondingly lower success rate. At our base case discount rate, total capitalized cost for a success rate of $23.5 \%$ is US\$ 734 million, or $8.5 \%$ lower than our base case result. At a success rate of $19.5 \%$, total capitalized cost is US\$ 885 million, or $10.3 \%$ higher than our base case result. The estimated clinical success rate for our previous study was $23.0 \%$. At that success rate, total capitalized cost here is US\$ 750 million, or $6.5 \%$ less than our base case result. ${ }^{26}$

The methodology for determining the total capitalized cost estimate is dependent on values for 20 parameters. However, not all of them are independent of one another. It is possible to determine total capitalized cost from estimates of 16 parameters. To get a measure of statistical error for overall cost, we performed a Monte Carlo simulation (1000 trials) for total capitalized cost by taking random draws from the sampling distributions of the 16 parameters and computing a total cost estimate for each simulation trial. ${ }^{27}$ Ninety-five percent of the total cost estimates for the simulation fell between US\$ 684 and 936 million, 90\% fell between US\$ 705 and 917 million, and 80\% fell between US\$ 717 and 903 million. ${ }^{28}$ The interquartile range was US\$ 757-854 million.

\footnotetext{
26 These analyses indicate what the results would be if the clinical success rate is changed, while other parameters remain the same. If the phase attrition rates are adjusted to be consistent with the new clinical success rate while maintaining the same distribution of failures across phases, then the differences in cost are somewhat lower. For example, if the clinical success rate is $23.0 \%$ and phase attrition rates are altered accordingly, total capitalized cost is $5.6 \%$ lower $(5.1 \%$ lower if account is also taken of estimated differences in phase costs between the failures and successes in the sample [see the following section]).

27 The clinical success rate parameter is determined from the values of four asymptotically normal coefficient estimates. We performed an initial Monte Carlo simulation for the clinical success rate using these coefficient estimates and their standard errors to obtain a sampling distribution for the success rate. The sampling distribution for the discount rate was chosen by assumption. Given that the base case choice of discount rate may be somewhat conservative (see the discussion above), we chose a triangular distribution for the discount rate that varied from 10.0 to $12.5 \%$, with the modal value for the distribution chosen so that the mean discount rate is approximately $11.0 \%$ in the simulations for total capitalized cost. The other sampling distributions were for estimated means and binomial probabilities. Finite population correction factors were applied to the standard errors.

28 The simulation was conducted assuming statistical independence for the parameters. The out-of- pocket phase cost, development time, and success and attrition rate parameters were estimated from separate datasets, and so their independence of one another is likely. It is possible that out-of- pocket phase costs are correlated. We therefore also conducted a simulation using the estimated correlations across phases for those pairs that were found to have correlations that were statistically significantly different from zero (phases I and II [0.496], phases II and III [0.430], phase II and long-term animal testing [0.656]). This increased the variability of the total capitalized cost estimates only slightly. Specifically, the coefficient of variation increased from 0.088 to 0.099 . The main simulation results were affected most by variability in individual phase costs, and least by variability in development times. The coefficient of variation when only development times vary, when only the discount rate varies, when only success and attrition rates vary, and when only out-of-pocket phase costs vary were $0.015,0.035,0.044$, and 0.065 , respectively.
} 


\subsection{Variable discount rates}

Myers and others (Myers and Shyam-Sunder, 1996; Myers and Howe, 1997) have argued that the cost-of-capital for R\&D should decline over the development process as a step function. They termed the relationship a risk-return staircase. In the case of pharmaceutical $\mathrm{R} \& \mathrm{D}$, the staircase is not related to the usual notions of risk in pharmaceutical development (i.e. the probabilities of approval at different points in the process). These technical risks can be diversified away by investors, who can spread their investments over many firms. Rather, the rationale has to do with the notion that at any point in the development process future $R \& D$ costs serve as a kind of leverage, or debt, if the firm wishes to proceed with development and market a product. A more levered position amplifies risk and is associated with a higher cost-of-capital for investors. Since the leveraging declines over the development process, so does the cost-of-capital. Technical risks play a role only in that they affect expected future costs.

The valuation problem may also be viewed as a compound option pricing problem. The firm effectively faces call options at decision points during development, where the exercise price is the cost of future R\&D. Myers and Howe (1997) suggest a means for dealing with the problem that reduces the informational requirements to knowledge of two-discount rates. One of these is the discount rate for net revenues on a marketed drug $\left(r_{\mathrm{NR}}\right)$. The other is the discount rate on future costs $\left(r_{\mathrm{FC}}\right)$. The rate for net revenues should be somewhat less than the overall company COC. The rate for future costs, being an expected return on what is nearly a fixed debt obligation, is likely lower. Under certain assumptions, the Myers and Howe (1997) two-discount rate method yields the same results as the more complex compound options valuation. We view this approach to discounting as experimental for our purposes. To our knowledge, no pharmaceutical firm uses such an approach for its project evaluations. In addition, although they may be guided by real world information, the selections of the two-discount rates are judgment calls. $^{29}$

For purposes of comparison, we did compute drug R\&D costs with the Myers and Howe (1997) two-discount rate method. Their base case values for $r_{\mathrm{NR}}(9 \%)$ and $r_{\mathrm{FC}}$ $(6 \%)$ were meant to be relevant for 1994 , which corresponds roughly with the middle of our study period. Thus, we computed the total capitalized pre-approval cost per approved drug using these values and other close combinations in a sensitivity analysis. At the Myers and Howe (1997) base case values, total capitalized cost is marginally higher than our estimate computed at an 11\% COC (US\$ 815 million). However, the total capitalized cost estimate is US\$ 955 million when a $10 \%$ discount rate is used for $r_{\mathrm{NR}}$ and a $5 \%$ discount rate is used for $r_{\mathrm{FC}}$. Conversely, at an $8 \%$ discount rate for $r_{\mathrm{NR}}$ and a $7 \%$ discount rate for $r_{\mathrm{FC}}$, the total cost estimate is US\$ 696 million.

\footnotetext{
${ }^{29}$ For their financial life-cycle simulation model, Myers and Howe (1997) chose base case values for $r_{\mathrm{NR}}$ and $r_{\mathrm{FC}}$ partly on the basis of judgment and partly because these values generated realistic company costs-of-capital for mature pharmaceutical firms in their simulations. These simulations required assumptions about revenue distributions and other factors that affect profitability.
} 


\section{Extensions to the base case}

The base case results on overall pre-approval drug development costs can be extended in several interesting ways. Our base case results link the costs of the failures to the successes. We can provide estimates of the clinical period cost of taking a successful drug all the way to approval by examining the data for the approved drugs in the sample. This also allows us to obtain some evidence on costs for the more medically significant products (according to what is known at the time of approval) by using an FDA prioritization ranking for approved drugs. We can also use data collected from our survey to estimate R\&D expenditures on new drugs subsequent to original marketing approval. Finally, we can examine what impact tax policies and procedures have had on the effective cost of pharmaceutical R\&D for pharmaceutical firms.

\subsection{Development costs for successes}

As our results indicate, development costs vary across drugs. Thus, it is worthwhile to examine specific subclasses of drugs, where one may reasonably conjecture that the cost structure is different than it is for drugs as a whole. In particular, we investigated the clinical cost structure for successful drugs (i.e. drugs that have made it through testing and obtained marketing approval from the FDA). We also examined these data classified by an FDA rating of therapeutic significance for drug approvals.

Of the 68 drugs in our sample, 27 have been approved for marketing. We had complete phase cost data for 24 of the approvals. Clinical phase cost averages and standard deviations for the approved drugs in the sample are shown in Table 5. For comparative purposes, the results for the full sample are also shown. Except for phase I, clinical phase costs are notably higher for the approved drugs than for drugs as a whole. Phase II and III costs for the approved drugs are 77 and $18 \%$ higher, respectively. This result is qualitatively consistent with what we found in our previous study. An explanation that we offered therein may still be appropriate. The results may reflect a tendency to prioritize development by directing more resources, possibly by conducting more studies concurrently, to investigational drugs that appear, after early testing, to be the most likely to be approved. Since we are not linking

Table 5

Out-of-pocket clinical period phase costs for approved compounds (in millions of 2000 dollars) ${ }^{\mathrm{a}}$

\begin{tabular}{|c|c|c|c|c|c|c|}
\hline \multirow[t]{2}{*}{ Testing phase } & \multicolumn{3}{|c|}{ Approved drugs ${ }^{b}$} & \multicolumn{3}{|c|}{ Full sample } \\
\hline & Mean cost & Median cost & $\begin{array}{l}\text { Standard } \\
\text { deviation }\end{array}$ & Mean cost & Median cost & $\begin{array}{l}\text { Standard } \\
\text { deviation }\end{array}$ \\
\hline Phase I & 15.2 & 11.7 & 14.3 & 15.2 & 13.9 & 12.8 \\
\hline Phase II & 41.7 & 31.5 & 30.2 & 23.5 & 17.0 & 22.1 \\
\hline Phase III & 115.2 & 78.7 & 95.0 & 86.3 & 62.0 & 60.6 \\
\hline Long-term animal & 4.4 & 0 & 5.4 & 5.2 & 3.1 & 4.8 \\
\hline
\end{tabular}

\footnotetext{
a All costs were deflated using the GDP Implicit Price Deflator.

${ }^{\mathrm{b}}$ Estimates for the approved drugs are based on data for 24 of the 68 sample drugs.

${ }^{c}$ Weighted values were used in calculating means, medians, and standard deviations for the full sample.
} 
failures to successes here and since we have full phase cost data for the 24 approved drugs, we can add phase costs for each drug to determine a total clinical period cost for each drug and use those data to find confidence intervals for mean out-of-pocket and capitalized clinical period cost for approved drugs. Mean out-of-pocket clinical period cost for the approved drugs was US\$ 176.5 million, with a 95\% confidence interval of US\$ 126-227 million. We used actual phase timing for individual approved drugs, rather than averages over all approved drugs, to capitalize costs for individual approved drugs. Doing so yielded a mean clinical period capitalized cost of US\$ 251.3 million, with a $95 \%$ confidence interval of US\$ 180.2-322.4 million.

The FDA prioritizes new drugs by therapeutic significance at the time of submission of an application for marketing approval. ${ }^{30}$ New drugs are rated as either priority $(\mathrm{P})$ or standard (S). ${ }^{31}$ Kaitin and Healy (2000), Kaitin and DiMasi (2000), Reichert (2000), and DiMasi (2001a) contain numerous analyses of development and approval times by FDA therapeutic rating. However, the only prior analysis of development costs by therapeutic rating was in our previous study. We found higher mean clinical phase costs for more highly rated drugs. The results for this sample also show higher costs. Mean clinical period out-of-pocket cost for approved drugs with a P rating was US\$ 207 million, compared to US\$ 155 million for drugs that had received the $\mathrm{S}$ rating.

The differential was less for capitalized costs. Mean clinical period capitalized cost was US\$ 273 million for drugs with a P rating and US\$ 236 million for those with the S rating. In both cases, the confidence intervals for $\mathrm{P}$ and $\mathrm{S}$ rated drugs overlap. However, given the substantial variability in drug development costs and the fact that the number of compounds in each category was small ( 10 drugs with a $\mathrm{P}$ rating and 14 with an $\mathrm{S}$ rating), this outcome is not surprising. However, it is plausible that, on average, testing a priority-rated drug breaks more new scientific ground and so is costlier, as firms must learn through experience. It may also be the case that firms have the incentive to do more wide-ranging and costly testing on drugs that have the potential to be both clinically and commercially significant. Our results can then be viewed as supportive, but not conclusive, evidence of higher costs for drugs with higher therapeutic significance ratings.

\subsection{Cost of post-approval $R \& D$}

Our main objective was to estimate pre-approval R\&D costs. However, our pre-approval estimates together with other pharmaceutical industry data regarding the drug development process allowed us to construct an estimate of the cost of post-approval R\&D, and thereby obtain an estimate of average total $R \& D$ cost per new drug covering the entire

\footnotetext{
30 The process is intended to provide direction for internal prioritization of marketing approval reviews by the FDA. The Prescription Drug User Fee Act of 1992 and its reauthorization in 1997 include performance goals for the FDA that are defined in terms of the therapeutic ratings.

31 In late 1992 the FDA switched from a three-tiered rating system (A, B, C) to the current two-tiered system (P, $\mathrm{S})$. Drugs that were rated A were judged to represent a significant gain over existing therapy, those rated B were judged to represent a moderate gain over existing therapy, and those rated $\mathrm{C}$ were judged to represent little or no gain over existing therapy. Our sample includes drugs that were rated under the old system. We assigned drugs that had received an $\mathrm{A}$ or $\mathrm{B}$ rating to the $\mathrm{P}$ category, and drugs that had received a $\mathrm{C}$ rating to the $\mathrm{S}$ category under the current system.
} 


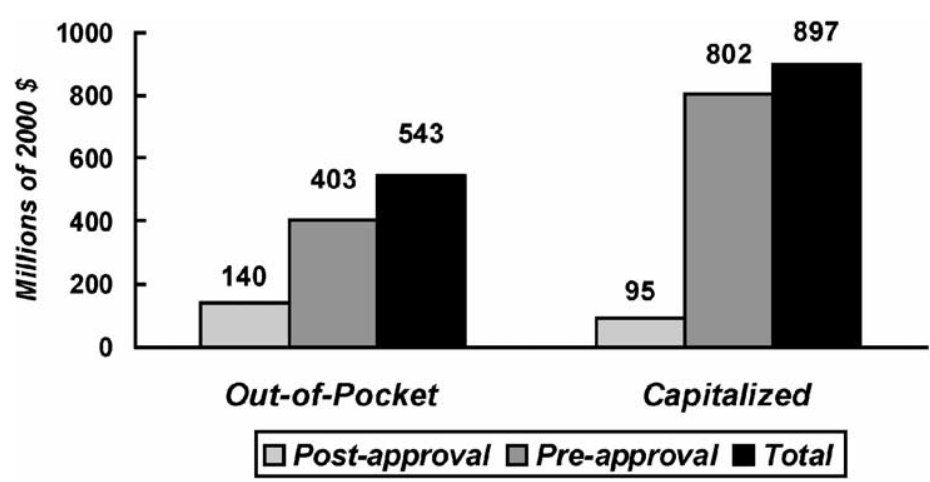

Fig. 4. Out-of-pocket and capitalized total cost per approved new drug for new drugs and for improvements to existing drugs.

development and marketing life-cycle. The aggregate annual expenditure data that we collected for the cost survey firms show that these firms spent approximately three-quarters of their prescription pharmaceutical R\&D expenditures on self-originated new drugs, $10 \%$ on investigational drugs that are licensed-in or otherwise acquired, and $15 \%$ on improvements to drugs that have already been approved.

We cannot, however, use the percentage of aggregate $R \& D$ expenditures spent on postapproval R\&D on a current basis and apply it to our pre-approval cost estimate to obtain an estimate of the cost of post-approval $R \& D$ per approved drug. The reason is that pre-approval costs occur years before post-approval costs. We may use our aggregate annual firm R\&D data, but we must build in a reasonable lag structure. Our methodology for doing so is discussed in detail in an appendix that is available from the authors upon request (Appendix A).

We used a 10-year lag for the aggregate data (approximate time between median preapproval development costs and median post-approval costs), assumed that post-approval R\&D cost per approval is the same, on average, for licensed-in and self-originated drugs, and determined the percentage of approvals for the cost survey firms that are self-originated to estimate the ratio of post-approval $\mathrm{R} \& \mathrm{D}$ cost per approved drug to pre-approval cost per approved drug. The data indicated that this share was $34.8 \%$. Thus, we estimated the out-of-pocket cost per approved drug for post-approval R\&D to be US\$ 140 million (Fig. 4). Since these costs occur after approval and we are capitalizing costs to the point of marketing approval, our discounted cost estimate is lower (US\$ 95 million). Thus, out-of-pocket cost per approved drug for post-approval R\&D is $25.8 \%$ of total R\&D cost (pre- and post-approval), while capitalized cost for post-approval R\&D is $10.6 \%$ of total cost.

\subsection{Tax analysis}

The cost estimates that are presented here are pre-tax. As noted above, OTA (1993) used the basic data and methodology from our previous study in their report, but the OTA also reported an after-tax figure determined by subtracting a percentage of pre-tax capitalized cost. The percentage was an assumed average effective corporate income tax rate for the 
period. Hence, a straightforward calculation can be made to use our R\&D cost estimates as inputs in after-tax analyses of R\&D rates of return (OTA, 1993; Grabowski and Vernon, 1994). However, some have suggested that an after-income tax figure is the relevant measure of pharmaceutical industry R\&D cost (Public Citizen, 2001).

As a stand-alone estimate for R\&D cost, we find such a figure to be inadequate for our purposes and potentially misleading. First, we are primarily interested in trends in private sector resource costs associated with getting a new drug to regulatory marketing approval. Tax rates and tax structures can change over time, so trends in resource costs can be masked by after-tax figures. Second, even if the objective is to measure the effective cost to companies, that cost is not properly measured by subtracting the corporate income tax deduction for R\&D from the resource cost estimate. It can also be misleading, as it may suggest that government is subsidizing corporate R\&D by the amount of the deduction. The corporate income tax is intended to be a tax on profits. Deductions for R\&D and other business costs are the means used to approximate the appropriate base for the tax (revenues minus costs). Thus, cost deductions on corporate income tax statements cannot be properly viewed as tax breaks.

The only potential tax advantage with respect to administration of the corporate income tax involves the timing of tax payments. $R \& D$ is an investment, but firms are allowed to deduct $R \& D$ costs (excluding plant and equipment) as current expenses in lieu of depreciating these investment costs over time. Nevertheless, the value of this timing effect should be significantly less than the total deduction. ${ }^{32}$ The accounting informational requirements needed to appropriately depreciate an intangible asset such as R\&D are so formidable that expensing of $\mathrm{R} \& \mathrm{D}$ is allowed under accounting guidelines. The true economic depreciation schedule likely varies significantly by industry, by firms within an industry, and by project within a firm. Thus, the practice of allowing what is in effect a $100 \%$ depreciation rate in the first year can be viewed as a second-best solution for an otherwise intractable issue.

A portion of the US tax code that is intended to serve as a stimulus to innovation by effectively subsidizing R\&D is the Research and Experimentation (R\&E) tax credit. The $R \& E$ tax credit was not relevant to a significant degree to the study period for our previous analysis (DiMasi et al., 1991). However, it is almost fully applicable to the study period for the current analysis. The credit is generally determined as a percentage of the excess of qualified $R \& D$ expenditures in a year over a base amount. It is difficult to adequately assess the quantitative impact of this tax policy. Over the history of the implementation of the $\mathrm{R} \& \mathrm{E}$ tax credit, the percentage credited has changed, as has the method for determining

\footnotetext{
32 In theory, optimal administration of the tax would involve depreciating all forms of intangible capital at economically appropriate rates. However, tax savings relative to the theoretical optimum should be measured in a tax revenue-neutral context. If intangible capital were depreciated rather than expensed, then the present value of tax revenues would increase. To keep revenues constant, the tax rate would have to be lowered. If all industries were identical with respect to the degrees to which they utilized intangible capital of all types, then tax burdens would not be any different in the alternative state (abstracting from any induced secondary effects on the distribution of industry allocations between tangible and intangible capital or between labor and capital). The pharmaceutical industry, however, is almost certainly above-average in terms of investment in intangible capital (Clarkson, 1977). If the optimal state is attainable at reasonable cost, the tax savings to the pharmaceutical industry, then, is not the difference in the present values of its tax burden as between the current state and the optimum at the current tax rate, but something less that depends on the extent to which the pharmaceutical industry is above-average with regard to investment in intangible capital.
} 
the base amount. ${ }^{33}$ It seems unlikely, though, that the credit has had a substantial economic impact on large multinational pharmaceutical firms. ${ }^{34}$

Since 1983 an orphan drug tax credit has also been available to manufacturers for clinical trial expenses related to the development of drugs for orphan indications (fewer than 200,000 patients afflicted in the United States or where it can be demonstrated that development is not profitable). However, for a number of reasons the empirical significance of this credit for the type of firm surveyed for this study is likely to be very small. ${ }^{35}$ Analysis of data provided in a Congressional Research Service (CRS) report indicates that orphan drug tax credits amount to a fraction of a percent of pharmaceutical industry R\&D expenditures (Guenther, 1999). ${ }^{36}$

\footnotetext{
${ }^{33}$ In the early implementation years the credit percentage was $25 \%$, but that was lowered to $20 \%$ in 1987 . The base amount had been an average of research expenditures that met certain criteria for the three previous tax years. In most instances it now essentially involves applying an historical R\&D-sales ratio (any 5 years from 1983 to 1988) to the average of gross receipts for the previous 4 tax years. The credit can be applied only to the excess of current "qualified research expenses" over the base amount. A variety of R\&D expenditures are excluded from consideration. For example, management expenses other than first-line supervision of those directly engaged in research activity, some computer software development costs, and 35\% of research expenses contracted out to for-profit firms are not counted. The credit also does not apply to research conducted outside the United States, Puerto Rico, or any possession of the United States. In addition, firms will typically elect to reduce the allowed credit by the maximum corporate income tax rate (currently 35\%). If they do not, then they must reduce the research expenses that they deducted on their corporate income tax statements by the amount of the credit.

${ }^{34}$ Many firms do not separately report R\&E tax credits in their published financial data. We did find R\&E credits reported in the public financial statements of seven large pharmaceutical firms for each year from 1999 to 2001 (GlaxoSmithKline, Johnson \& Johnson, Lilly, Pfizer, Pharmacia, Schering-Plough, and Takeda) and for 2001 for American Home Products (now Wyeth). We compared the credit amounts to the firms' reported R\&D expenses. R\&E credits as a percentage of R\&D expenditures varied somewhat by firm and year $(0-5.2 \%)$. Overall, the tax credits amounted to $2.0 \%$ of R\&D expenditures. Adding Merck, which reported on a broader category (General Business Credits), increased the share only to $2.1 \%$. One might argue that prescription pharmaceutical $R \& D$ could contribute more to the accumulation of $R \& E$ tax credits than is indicated by these data. This might be so if prescription pharmaceutical R\&D expenditures grow more rapidly than the firms' other R\&D expenditures (this effect would be mitigated, though, in the long-run if pharmaceutical sales also increase at a rate that is greater than for the firms' other businesses). We do not know if this has been the case. However, even if it has, that impact could be more than reversed if firms have made greater use of outsourcing in pharmaceutical than in non-pharmaceutical R\&D. By all accounts, pharmaceutical firms have contracted out drug development activities at a rapidly growing rate over our study period, and the share of pharmaceutical R\&D expenditures currently accounted for by outsourcing is substantial. As noted above, a significant share of outsourced R\&D is excluded from the tax credit calculations.

${ }^{35}$ Unless it can be demonstrated that it is necessary to go outside the United States to find patients, the credit (50\% of qualified clinical trial expenses) is not available for foreign trial costs. It is also cannot be applied to clinical testing on any non-orphan indications for a compound with an orphan drug designation. In addition, the vast majority of the manufacturers with products that have received orphan drug designations are biotech firms or small niche pharmaceutical firms (see http://www.fda.gov/orphan/designat/list.htm). For development as a whole, it is highly likely therefore that the share of R\&D expenditures for which the orphan drug credit was applicable for traditional large multinational pharmaceutical firms is quite low.

36 The report includes data on both orphan drug tax credits and taxable income for the pharmaceutical industry for 1990-1994. The CRS also noted in its report that $20.3 \%$ of US pharmaceutical industry domestic sales and exports were spent on $R \& D$ in 1997. Applying this R\&D-sales ratio to the data on taxable income suggests that orphan drug credits amounted to $0.3 \%$ of $R \& D$ expenditures. This is a conservative estimate for large pharmaceutical firms since taxable income is determined by deducting business expenses from sales, and since, as noted above, biotechnology and small pharmaceutical firms obtain a disproportionate share of the credits.
} 


\section{Validation}

In their 1993 report, the OTA reviewed the literature on pharmaceutical R\&D costs. In addition to critiquing the methodologies used in these studies, the review addressed evidence on the reasonableness of the studies, particularly the DiMasi et al. (1991) study. The OTA concluded that, "the estimates by DiMasi and colleagues of the cash outlays required to bring a new drug to market and the time profile of those costs provide a reasonably accurate picture of the mean R\&D cash outlays for NCEs first tested in humans between 1970 and 1982" (OTA, 1993, p. 66). The OTA provided varied data and analyses to corroborate the results in DiMasi et al. (1991). We corroborate the basic cost results in this study by examining the representativeness of our sample firms and by analyzing various independently derived results and data about the industry and the drug development process. We pay particular attention to data that corroborate the growth in costs between the previous study and the current one.

\subsection{Internal validation}

The Tufts CSDD database of investigational compounds, from which our sample was selected, contains data on the vast majority of new drugs developed in the United States (DiMasi, 2001a). The distribution of investigational drugs across therapeutic classes for our 10 survey firms is very close to the distribution for all drugs in the database. We examined the data for eight specific therapeutic classes and one miscellaneous class for drugs in the database that met study inclusion criteria. There are 530 compounds in the database that meet these criteria and for which a therapeutic class could be identified ( 272 of these compounds belong to the 10 cost survey firms). The largest difference in share for a specific class between all firms in the database and the cost survey firms was $1.5 \% .{ }^{37}$ Using a chi-squared goodness-of-fit test comparing the therapeutic class distributions for the cost survey firms and the other firms in the database, we found no statistically significant difference for the class shares $\left(\chi^{2}=5.01\right.$, d.f. $\left.=9\right){ }^{38}$

Based on publicly available data, we also found that pharmaceutical R\&D expenditure growth rates for the survey firms as a whole were similar to the reported growth rates for all PhRMA member firms. For example, the annual growth rate in real pharmaceutical R\&D expenditures for the survey firms ${ }^{39}$ from 1995 to 2000 is $11.3 \%$, compared to $11.0 \%$ for PhRMA member firms over the same period. ${ }^{40}$

\footnotetext{
37 The population shares for the analgesic/anesthetic, antiinfective, antineoplastic, cardiovascular, central nervous system, endocrine, gastrointestinal, immunologic, miscellaneous, and respiratory classes are 9.1, 12.8, 9.4, 23.2, $17.9,7.0,2.1,3.0,9.4$, and $6.0 \%$, respectively. The corresponding shares for the cost survey firms are 9.6, 14.3, $8.1,22.8,19.1,7.4,2.2,3.3,7.7$, and $5.5 \%$, respectively.

38 The estimated clinical success rate for all firms in this dataset $(21.5 \%)$ is also very close to the estimated success rate for the 10 firms using the same inclusion criteria $(22.2 \%)$.

39 The data are for nine of the 10 firms. We did not find pharmaceutical R\&D data for one of the firms, but this firm has a relatively small pharmaceutical subsidiary whose inclusion would not materially affect the results. The data were taken from Scrip's Pharmaceutical Company League Tables (various years) and company annual reports.

40 The annual growth rate for 1995-1999 was slightly lower for the survey firms compared to all PhRMA member firms $(11.5 \%$ versus $11.8 \%)$.
} 


\subsection{External validation}

Publicly available data that were collected independently can be examined to determine the extent to which they are consistent with our results in terms of levels or rates of change. Specifically, we examined independent information on clinical trial sizes, measures of clinical trial complexity, and published trade association data on R\&D employment and expenditures.

\subsubsection{Clinical trial sizes and complexity}

Several groups have compiled data on clinical trial sizes for new molecular entities approved in the United States for periods that range from the late 1970s to 2001 (BCG, 1993; OTA, 1993; Peck, 1997; PAREXEL, 2002). ${ }^{41}$ Averaging the BCG results for 1981-1984 and 1985-1988 (2277) and comparing them to average of the Peck (1997) and PAREXEL (2002) results for 1994-1995 and 1998-2001 (5603) yields an annual growth rate in clinical trial sizes of $7.47 \%$ per year. ${ }^{42}$ We may approximate the increases in cost per subject over time by examining the excess of medical care inflation over general price inflation. The medical care component of the CPI increased at an average annual rate of $6.73 \%$ from 1984 to 1997, while general price inflation (applying the price index used to deflate costs for this study) rose at an annual rate of $3.06 \%$ over the same period. Thus, other things being equal, these results suggest an increase of $11.4 \%$ per year in clinical trial costs. This compares to our finding of an $11.8 \%$ annual growth rate in out-of-pocket clinical period cost between DiMasi et al. (1991) and the current study.

These separate estimations need not be in perfect agreement because our clinical cost figures include costs not directly related to the number of clinical trial subjects (infrastructure costs, fixed costs related to production of clinical trial supplies, animal testing during the clinical period, etc.). In addition, there could be some economies of scale in clinical testing that would result in a somewhat lower growth in cost per subject. However, data compiled by DataEdge, LLC (PAREXEL, 2002, p. 96) indicate that the complexity of clinical trials

\footnotetext{
${ }^{41}$ Each of these sources obtained data for a sample of the US approvals during specific periods. The BCG found the mean number of subjects included in NDAs to be 1576 for 1977-1980, 1321 for 1981-1984, and 3233 for 1985-1988. OTA (1993) compared clinical trial sizes for NDAs for three therapeutic categories (antihypertensives, antimicrobials, and nonsteroidal antiinflammatories) over two periods. In aggregate, it found the mean number of subjects to be 2019 for $1978-1983$ approvals $(n=28)$ and 3128 for $1986-1990$ approvals $(n=25)$. Peck (1997) found the mean number of subjects to be 5507 for 12 of 50 1994-1995 approvals. PAREXEL (2002) has examined the number of subjects in NDAs for 55\% of the new molecular entities approved by the FDA in each year from 1998 to 2001 . For the period as whole, the mean number of subjects is $5621(n=64)$. The latter two averages are similar to what we have found as the mean number of subjects across all three clinical phases for the investigational drugs in our cost survey (5303). CMR (2000) found the mean number of subjects to be 4478 for 23 marketing approval applications submitted from 1995 to 2000 . However, only nine of the submissions were to the FDA, with the remainder submitted to European Union and Japanese regulatory authorities. Since pre-approval costs are measured here up to the point of US regulatory approval, we use the USbased data.

42 These groupings were chosen so that the mean approval years were 1984 and 1997 (the average approval years for the DiMasi et al. (1991) and the current cost samples). The difference in the two periods was taken to be 12.5 years. For the early period, we prefer the BCG data to the OTA data, since the OTA data apply to only three therapeutic categories that likely tend, in aggregate, to have above-average clinical trial sizes.
} 
has increased significantly in recent years. Their index of clinical trial complexity ${ }^{43}$ for phases I-III increased at an annual rate of $4.8 \%$ per year from 1992 to 2000. An increase in clinical trial complexity will contribute to even higher growth rates for clinical costs. ${ }^{44}$

\subsubsection{Growth in industry $R \& D$ employment costs}

Despite rapid growth in outsourcing of $R \& D$ activities over the last few decades, pharmaceutical firms have significantly expanded the number of their own employees devoted to the R\&D function. In its industry profile and annual survey reports over various years, PhRMA has provided annual information on the R\&D employment of its member firms. From 1980 to 2000 , total R\&D employment increased at a compound annual rate of $5.4 \%$, with scientific and professional staff increasing at a $7.4 \%$ annual rate. ${ }^{45}$

We adjusted National Science Foundation (NSF) data on median annual salaries for full-time employed biological scientists with doctorates working in for-profit life sciences industries from 1993 to 1999 for inflation (GDP Implicit Price Deflator). ${ }^{46}$ Real salaries increased at a rate of $1.75 \%$ per year over this period. The OTA presented similar data for every 2 years from 1973 to 1989 (OTA, 1993; pp. 62-63). The real growth rate in median annual salaries for biological scientists with doctorates employed in business or industry from 1981 to 1989 was $1.77 \%$. Applying a real growth rate of $1.76 \%$ per year for compensation to a growth rate of $7.4 \%$ per year in employment yields a growth rate of $9.3 \%$ per year for labor costs. This is moderately higher than the growth rate of $7.6 \%$ per year that we found for total out-of-pocket cost per approved drug between our previous study and the current one. ${ }^{47}$ Thus, some labor costs have grown fairly rapidly. Most of the growth in labor costs, though, has been due to increasing the labor force devoted to R\&D, rather than to increases in real wages.

\footnotetext{
43 The index is based on the mean number of medical procedures to be applied to patients in clinical trial protocols. Some of these procedures will be covered by insurance, but the index should provide at least a rough indicator of the degree to which the clinical trial process is increasing in complexity.

44 DataEdge has also compiled information on certain clinical trial costs (investigator fees and central laboratory costs). Changes in cost due to increases in clinical trial complexity will be at least partially reflected in these data. PAREXEL (2002) reports their index of mean costs per subject across all clinical phases (I-IV) for each year from 1996 to 2000. The index increased at an average annual real rate of 5.33\% over this period. Combining this growth rate with the above growth rate for clinical trial sizes suggests a $13.1 \%$ average annual real rate of increase in clinical trial costs. Piecing together the index values for years reported in earlier editions of PAREXEL (2002) yields a $3.54 \%$ real growth rate for 1993-2000. This would imply an $11.2 \%$ average annual real growth rate in clinical trial costs.

45 Over our study period, highly trained personnel have comprised an increasingly large component of the pharmaceutical industry in-house R\&D labor force. The share of total R\&D personnel for the scientific and professional category in the PhRMA data increased from $56.3 \%$ in 1980 to $81.8 \%$ in 2000 .

46 The data were compiled for 1993, 1995, 1997, and 1999 by the NSF through surveys of doctoral scientists and engineers in the United States (National Science Foundation, various years). The NSF used a new survey instrument for 1993 and later. Data for every 2 years from 1973 to 1989 used somewhat different occupational definitions. Thus, these data may not be strictly comparable to the data for 1993 and beyond. Data were not available for 1991 .

47 The NSF survey data for 1993-1999 show a real increase of 1.2\% per year in median annual salaries across all degrees for biological scientists working in the for-profit life sciences industries. Applying this growth rate to the growth rate of $5.4 \%$ for all pharmaceutical industry R\&D personnel yields an increase of $6.7 \%$ per year in labor costs.
} 


\subsubsection{Cost estimates from published industry $R \& D$ expenditures}

PhRMA has gathered information on aggregate industry R\&D spending for decades. The resultant $R \& D$ expenditure time series can be linked to data on new drug approvals to develop rough estimates of out-of-pocket pharmaceutical R\&D costs. As noted above, linking current expenditures to current approvals is an inadequate approach. Our estimated time profile for a representative drug and the pattern of costs over that timeline determined for this study can be used to construct a lag structure for aggregate expenditures and approvals. ${ }^{48}$

There are two complications regarding the PhRMA data that must be addressed before we can validate our estimates. One is that while PhRMA has traditionally disaggregated its reported $\mathrm{R} \& \mathrm{D}$ expenditure data into expenditures on new drugs and expenditures on improvements to existing drugs, it has not gathered information on how expenditures on new drugs can be further decomposed into expenditures on self-originated and on licensed-in new drugs. Our R\&D cost estimates are for self-originated drugs, and a substantial portion of the $R \& D$ expenditures on licensed-in drugs are likely missing from the PhRMA data. ${ }^{49}$ Thus, we need to associate lagged industry expenditures on self-originated new drugs with self-originated new drug approvals. The second complication is that, with the exception of 1 year, PhRMA has gathered information on the domestic expenditures of all its firms, but the foreign expenditures of only its US-owned members. Our method for dealing with these complications is described in detail in an appendix available from the authors upon request (Appendix B).

We related estimated lagged PhRMA member firm R\&D expenditures on self-originated new drugs from 1978 to 1998 to the number of self-originated new drug approvals by PhRMA member firms from 1990 to 2000 . The lag structure follows the phase time-expenditure profile implied by our data, with weights attached to aggregate expenditures over a 2-12 year period. The ratio of total lagged self-originated $R \& D$ expenditures to the total number of self-originated approvals yields an estimate of the out-of-pocket cost of new drug

\footnotetext{
48 PhRMA also publishes a breakdown of annual R\&D expenditures of its member firms by function (PhRMA, 2001). The share for the category "Clinical Evaluation: Phases I-III" in 1999 is $29.1 \%$. This share cannot be compared to the clinical period share of total out-of-pocket cost per approved drug implied by our estimates for at least three reasons. First, clinical period costs in a given year are linked to pre-human R\&D expenditures in past years, and the pharmaceutical R\&D expenditure series shows substantial growth. Thus, shares based on current year expenditures will significantly understate the clinical portion. Second, portions or all of some categories are for expenditures on post-approval R\&D and should be deducted from the base before a pre-approval clinical share is computed. For example, given their definitions, the categories for "Clinical Evaluation: Phase IV (11.7\%)" and "Process Development for Manufacturing and Quality Control (8.3\%)" would likely have to be taken entirely out of the base. In addition, portions of other categories also likely are associated with post-approval R\&D. Third, our notion of clinical period costs extends beyond direct patient costs and includes fixed infrastructure costs and other costs incurred during the clinical period. The categories "Toxicology and Safety Testing (4.5\%)," Pharmaceutical Dosage Formulation and Stability Testing (7.3\%)," "Regulatory: IND and NDA (4.1\%)," "Bioavailability (1.8\%)," and "Other (9.0\%)" would each have to be decomposed into shares for pre-human R\&D, pre-approval clinical period R\&D, and post-approval R\&D. With a reasonable pre-human/clinical lag structure, it is possible to choose an allocation of the three periods for these functional categories that results in a clinical period share of pre-approval $R \& D$ expenditures that equals our estimated cost share. However, we are not aware of any data that allows one to make these allocations credibly. Thus, we concluded that the PhRMA data on functional categories could not be used as an external check on our results.

49 The PhRMA data apply to member firms. Not every pharmaceutical firm (particularly foreign firms) and few biotechnology firms are members of the organization.
} 
development. ${ }^{50}$ We calculated a range for this ratio by using reported domestic industry $\mathrm{R} \& \mathrm{D}$ expenditures for a lower bound and domestic plus foreign (inclusive of estimates for foreign-owned firms) industry R\&D expenditures as an upper bound. The result is a range of US\$ 354-558 million for out-of-pocket cost per approved new drug (inclusive of failures). Our out-of-pocket cost estimate of US\$ 403 million per approved drug calculated from our survey data falls within this range. Capitalizing the aggregate expenditure data using our phase-expenditure time profile yields a range of US\$ 650-1023 million, which encompasses our total capitalized cost estimate of US\$ 802 million.

We also conducted a check similar to what the OTA had done in its report (OTA, 1993, pp. 61-62). In theory, under our average development and approval time profile described above, all industry self-originated new drug R\&D expenditures in 1988 would be associated with new drug approvals from 1990 to 2000. If each self-originated new drug approval from 1990 to 2000 by a PhRMA member firm is assumed to cost US\$ 403 million, then we can use the yearly time-expenditure weights noted above to estimate PhRMA member firm total self-originated R\&D expenditures in 1988. Doing so yields US\$ 6176 million in 2000 dollars. This value fits within our range for self-originated new drug R\&D expenditures estimated from the PhRMA data (US\$ 4942-7777 million in 2000 dollars).

\section{Conclusions}

The cost of developing new drugs is a topic that has long engendered considerable interest. The interest has intensified recently as firms have become increasingly concerned about improving productivity in a period of consolidation and cost containment pressures in the marketplace, and industry critics question industry statements about the level of R\&D costs and the impact that price regulation would have on R\&D (Public Citizen, 2001). ${ }^{51}$ We have undertaken the only comprehensive project-based analysis of the costs of drug development since our previous study (DiMasi et al., 1991). In the last study we estimated average R\&D cost to be US\$ 231 million in 1987 dollars. For our updated analysis, we estimated that total R\&D cost per new drug is US\$ 802 million in 2000 dollars. Our results were validated in an number of ways through analyses of independently derived published data on the pharmaceutical industry. Including an estimate of the cost per approved new drug for R\&D conducted after approval increases total R\&D cost to nearly US $\$ 900$ million. Our pre-approval estimate represents a two and one-half-fold increase in real capitalized costs. On an annualized basis, the growth rate in inflation-adjusted cost was $7.6 \%$ for out-of-pocket expenditures and $7.4 \%$ for capitalized costs.

Roughly speaking, the current study covers R\&D costs that yielded approvals, for the most part, during the 1990s. The previous study (DiMasi et al., 1991) generally involved

\footnotetext{
${ }^{50}$ We believe that aggregating over the expenditure and approval periods is superior to using an average of yearly ratios. Year-to-year ratios are highly variable since they are very sensitive to the denominator value (number of self-originated new drug approvals) for the year.

${ }^{51}$ Pre-approval $R \& D$ expenditures are sunk costs at the time a pricing decision has to be made. Thus, they should not affect price setting in an unregulated market. However, to the extent that high past R\&D costs predict high future R\&D costs, then anticipated or realized stringent price regulation can significantly reduce incentives to innovate and thereby negatively impact future drug development.
} 
R\&D for 1980s approvals, and the first study in this series (Hansen, 1979) was mainly relevant to 1970 s approvals. While the compound annual growth rates in out-of-pocket costs between successive studies were similar $(7.0 \%$ per year between the first two studies and $7.6 \%$ per year between the last two), the rates of increase for the two major R\&D phases were quite different. Although both preclinical and clinical period costs increased in real terms in this study, the rate of increase for the preclinical period was less than one-third that for the first two studies, while the growth rate for clinical costs was nearly twice as high for the two most recent studies.

Our data do not allow us to test hypotheses about factors that affect how costs change over time, but some conjectures can be made. For example, over the periods analyzed the pharmaceutical industry has increasingly focused on developing treatments for chronic and degenerative diseases or conditions associated with those diseases. ${ }^{52}$ Therapies for such conditions are generally more costly to test, as they typically require more complex patient care and monitoring, longer periods for effects to be observed, or larger trial sizes to establish their efficacy.

When the study periods analyzed for the previous study and the current one are compared, one observes that the number of new drugs approved increased over time, as did the number of drugs investigated. This can be associated with patient recruitment that is more time-consuming and costlier.

Finally, the development of more stringent cost containment strategies in the United States and abroad such as tiered formularies and the demand for cost-effectiveness results may have led firms to test their drugs more often against competitor products already on the market (F-D-C Reports, 1999). This will generally be costlier than testing against placebo; the trials will likely need to be more highly powered (i.e. clinical trial sizes will have to be higher) to establish a statistical difference.

These factors help explain the growth in clinical period costs. Preclinical (discovery and preclinical development) costs also grew in real terms, but much more slowly than in the past. The widespread use of discovery technologies, such as combinatorial chemistry techniques and high-throughput screening, during the current study period may have created enough efficiency gains to slow down the growth of preclinical costs.

The cost growth rates that we have observed are substantial. There is no guarantee that they will continue at these levels, but we can determine where costs would end up if they did. The average approval date for our sample was in 1997. Assuming the same growth rates for out-of-pocket and capitalized costs, then the out-of-pocket pre-approval cost per approved drug for R\&D relevant to approvals in 2001 would be US\$ 540 million, while capitalized pre-approval cost would be US\$ 1.1 billion. If growth rates were maintained and R\&D was initiated in 2001 with approvals obtained 12 years later, then pre-approval out-of-pocket cost would rise to US\$ 970 million and pre-approval capitalized cost would rise to US\$ 1.9 billion.

A number of technical factors can work to alter the growth pattern for future R\&D costs. We observed improved clinical phase attrition rates for the current study. If firms

\footnotetext{
52 We have in mind a broader concept than chronic use drugs. The conditions treated may require drugs that are used on a short-term, medium-term, or intermittent basis. These conditions may result from the natural course of a chronic disease or they may occur as side effects from direct treatment of such complex diseases.
} 
can further improve their performance in terminating research early for compounds that will not make it to approval, then this will help lower out-of-pocket and capitalized costs. Reductions in development times, other things being equal, would also lower capitalized costs. Some recent evidence on clinical development times suggest a shortened process, at least in the United States (Kaitin and DiMasi, 2000; DiMasi, 2001a), but it is too soon to conclude that we are observing a new trend. Finally, emerging discovery and development technologies may have profound effects on $R \& D$ productivity. Industry analysts that have recently examined the impact that genomics and other new technologies may have on the $R \& D$ process have suggested that as pharmaceutical firms increasingly embrace the new approaches, R\&D costs may actually rise significantly in the short run (Pharma Marketletter, 2001; Tollman et al., 2001). The major reason is that the new technologies may generate many targets that are currently not well understood. Eventually, though, they argue that the science knowledge base will expand sufficiently so that efficiencies will be realized.

Analyses of private sector R\&D costs provide a crucial input to policy-oriented studies. For example, R\&D cost estimates can be utilized in studies that aim to measure the ex-post profitability of new drug development for a given period. This is a timely issue given recent media attention on $R \& D$ productivity issues and problems in the $R \& D$ pipelines of many leading firms (Pollack, 2002). Results from our prior studies have in fact been used in analyses of the rate of return to pharmaceutical R\&D (Grabowski and Vernon, 1990; OTA, 1993; Grabowski and Vernon, 1994). ${ }^{53}$ These studies of the profitability of new drug development have not found evidence of significant and sustained excess profits. The estimated internal rates of return are quite close to the cost-of-capital. The much higher $R \& D$ cost estimates for this study raise a question about the recent profit experience of the pharmaceutical industry. However, Grabowski and Vernon (2000) found substantial growth in pharmaceutical sales for 1990s drug cohorts. A new study (Grabowski et al., 2002) on pharmaceutical profitability using some of the cost results in this study and recent sales data is qualitatively consistent with the outcomes of the earlier profitability studies (i.e. the internal rate of return is close to the industry cost-of-capital).

Data on R\&D costs can also be helpful in analyzing the impact on R\&D returns from policy changes that affect the intellectual property protection system, drug development times, or FDA approval times, and therefore influence private incentives to innovate. The Congressional Budget Office (CBO), for example, examined the net effect on pharmaceutical industry returns that the Drug Price Competition Act of 1984 had from simultaneously reducing the cost of generic entry and increasing effective patent lifetimes (CBO, 1998). Simulations of proposed policy changes for these and other variables that affect the costs of and returns to pharmaceutical R\&D can similarly be conducted using our new estimates.

The relationship between pharmaceutical industry profitability and investment in R\&D has recently been examined in Scherer (2001). The author found a high degree of correlation between the deviations from trend for the time series on pharmaceutical industry $R \& D$ expenditures and on gross margins, indicating that $R \& D$ outlays are affected significantly

\footnotetext{
53 As noted above, tax issues are explicitly considered in such studies. The corporate income tax, however, plays a very limited role in such analyses. The reason is that the tax essentially enters symmetrically in the analysis (applied to revenues as well as costs), and so the impact on the internal rate of return is minimal. The net present value of profits, though, is lower because of the tax.
} 
by changes in profitability. The growth rate for gross margins for recent years was also substantially lower than the growth rate for R\&D outlays, leading to the suggestion that $\mathrm{R} \& \mathrm{D}$ growth rates could lessen in the future. If that were to happen, one might ask what would happen to R\&D costs. This would depend on the outcome of internal rate of return analyses by firms on marginal projects. ${ }^{54}$ The ultimate impact on future costs, however, will also depend on whether and to what degree currently unforeseen biomedical advances that expand scientific opportunities will be realized.

Finally, our results indicate that variability in drug development costs has declined somewhat but is still substantial. For an earlier period, DiMasi et al. (1995a) found varying average clinical period costs for a number of major therapeutic classes. We will examine costs by therapeutic category in future research. For that same earlier period, DiMasi et al. (1995b) also found that average R\&D costs tended to decrease with firm size. The structure of the traditional pharmaceutical industry appears to have evolved somewhat since then. Examining new drug output levels by firm, DiMasi (2000) found both a long-term deconcentration trend for the research-based pharmaceutical industry and substantial new entry during the 1990s with respect to traditional small molecule output. The R\&D cost data for this study can be used in further analyses of $R \& D$ productivity at the firm level in future research.

\section{Acknowledgements}

We thank two anonymous referees and the editors for helpful comments. All errors and omissions are the responsibility of the authors. We also thank the surveyed firms for providing data, and individuals in those firms who kindly gave their time when we needed some of the responses clarified. The authors did not receive any external funding to conduct this study.

\section{References}

Boston Consulting Group, 1993. The Contribution of Pharmaceutical Companies: What's at Stake for America. The Boston Consulting Group, Boston, MA, September 1993.

US Congressional Budget Office, 1998. How Increased Competition from Generic Drugs has Affected Prices and Returns in the Pharmaceutical Industry. US Government Printing Office, Washington, DC, July 1998.

Clarkson, 1977. Intangible Capital and Rates of Return, American Enterprise Institute, Washington, DC.

CMR, 2000. Describing Dossiers: Characterising Clinical Dossiers for Global Registration. R\&D Briefing 25, CMR International, Surrey, UK.

DiMasi, J.A., Hansen, R.W., Grabowski, H.G., Lasagna, L., 1991. Cost of innovation in the pharmaceutical industry. Journal of Health Economics 10, 107-142.

DiMasi, J.A., Hansen, R.W., Grabowski, H.G., Lasagna, L., 1995a. Research and development costs for new drugs by therapeutic category: a study of the US pharmaceutical industry. PharmacoEconomics 7, 152-169.

\footnotetext{
54 While one might postulate that higher cost projects would be more vulnerable, firms should take account of expected profitability. Given that we found some evidence of higher costs for more innovative products, if firms elect to focus more on innovative projects on expected profitability grounds, average costs would increase when economically marginal projects are dropped.
} 
DiMasi, J.A., Grabowski, H.G., Vernon, J., 1995b. R\&D costs, innovative output and firm size in the pharmaceutical industry. International Journal of the Economics of Business 2, 201-219.

DiMasi, J.A., 2000. New drug innovation and pharmaceutical industry structure: trends in the output of pharmaceutical firms. Drug Information Journal 34, 1169-1194.

DiMasi, J.A., 2001a. New drug development in the United States 1963-1999. Clinical Pharmacology \& Therapeutics 69, 286-296.

DiMasi, J.A., 2001b. Risks in new drug development: approval success rates for investigational drugs. Clinical Pharmacology \& Therapeutics 69, 297-307.

F-D-C Reports, 1999. NDA Submissions are Shrinking in Size but Increasing in Complexity. The Pink Sheet 61, p. 28.

Grabowski, H.G., Vernon, J., 1990. A new look at the returns and risks to pharmaceutical R\&D. Management Science 36, 804-821.

Grabowski, H.G., Vernon, J., 1994. Returns to R\&D on new drug introductions in the 1980s. Journal of Health Economics 13, 383-406.

Grabowski, H.G., Vernon, J., 2000. The distribution of sales revenues from pharmaceutical innovation. PharmacoEconomics 18 (Supplement 1), 21-32.

Grabowski, H.G., Vernon, J., DiMasi, J.A., 2002. Returns on research and development for 1990s new drug introductions. PharmacoEconomics 20 (Supplement 3), 11-29.

Guenther, G., 1999. Federal taxation of the drug industry from 1990 to 1996. Memorandum to Joint Economic Committee, US Congress, Congressional Research Service, 13 December 1999.

Hansen, R.W., 1979. The pharmaceutical development process: estimates of current development costs and times and the effects of regulatory changes. In: Chien, R.I. (Ed.), Issues in Pharmaceutical Economics. Lexington Books, Lexington, MA, pp. 151-187.

Ibbotson Associates, 2001. Stocks, Bonds, Bills \& Inflation: 2001 Yearbook, Ibbotson Associates, Chicago, Illinois.

Kaitin, K.I., Healy, E.M., 2000. The new drug approvals of 1996, 1997, and 1998: drug development trends in the user fee era. Drug Information Journal 34, 1-14.

Kaitin, K.I., DiMasi, J.A., 2000. Measuring the pace of new drug development in the user fee era. Drug Information Journal 34, 673-680.

Myers, S.C., Shyam-Sunder, L., 1996. Measuring pharmaceutical industry risk and the cost-of-capital. In: Helms, R.B. (Ed.), Competitive Strategies in the Pharmaceutical Industry. American Enterprise Institute, Washington, DC, pp. 208-237.

Myers, S.C., Howe, C.D., 1997. A life-cycle financial model of pharmaceutical R\&D. Working Paper, Program on the Pharmaceutical Industry. Massachusetts Institute of Technology, Cambridge, MA.

National Institutes of Health, 2000. NIH Response to the Conference Report Request for a Plan to Ensure Taxpayers' Interests are Protected: A Plan to Ensure Taxpayers' Interests are Protected. National Institutes of Health, Rockville, MD, July 2001.

US Congress, Office of Technology Assessment, 1993. Pharmaceutical R\&D: Costs, Risks, and Rewards, OTA-H-522. US Government Printing Office, Washington, DC.

Peck, C.C., 1997. Drug development: improving the process. Food and Drug Law Journal 52, 163-167.

Pharma Marketletter, 2001. Genomics may increase costs of NCE development, says Lehman Bros. Pharma Marketletter, vol. 28, 26 February 2001, pp. 24-25.

PhRMA, 2000. Pharmaceutical Industry Profile 2000: Research for the Millennium, Pharmaceutical Research and Manufacturers of America, Washington, DC.

PhRMA, 2001. Pharmaceutical Industry Profile 2001, Pharmaceutical Research and Manufacturers of America, Washington, DC.

PJB Publications Ltd., 2000. Scrip's 2000 Pharmaceutical Company League Tables, Richmond, Surrey, UK, 3 November 2000.

Pollack, A., 2002. Despite Billions for Discoveries, Pipeline of Drugs is Far from Full. New York Times, 19 April 2002.

Public Citizen, 2001. Rx R\&D Myths: The Case Against the Drug Industry’s R\&D Scare Card, Public Citizen, Congress Watch, July 2001.

Reichert, J.M., 2000. New biopharmaceuticals in the US: trends in development and marketing approvals 1995-1999. Trends in Biotechnology 18, 364-369. 
Scherer, F.M., 2000. The pharmaceutical industry. In: Newhouse, J.P. (Ed.), Handbook of Health Economics, vol. 1. Elsevier, Amsterdam, Chapter 25, pp. 1297-1336.

Scherer, F.M., 2001. The link between gross profitability and pharmaceutical R\&D spending. Health Affairs 20, 216-220.

Tollman, P., Guy, P., Altshuler, J., Flanagan, A., Steiner, M., 2001. A Revolution in R\&D: The Impact of Genomics. The Boston Consulting Group, Boston, MA, June 2001.

US Food and Drug Administration, Center for Drug Evaluation and Research, 1999. From Test Tube to Patient: Improving Health Through Human Drugs (special report). US Government Printing Office, Washington, DC, September 1999 (http://www.fda.gov/fdac/special/newdrug/ndd_toc.html). 